\title{
Characterization of abscopal effects of intratumoral electroporation- mediated IL-12 gene therapy
}

\author{
Anandaroop Mukhopadhyay ${ }^{1} \cdot$ Jocelyn Wright ${ }^{1} \cdot$ Shawna Shirley $^{1} \cdot$ David A. Canton $^{1} \cdot$ Christoph Burkart $^{1}$. \\ Richard J. Connolly ${ }^{1,2} \cdot$ Jean S. Campbell ${ }^{2} \cdot$ Robert H. Pierce $\mathbb{B}^{2}$
}

Received: 26 March 2018 / Revised: 20 August 2018 / Accepted: 12 September 2018 / Published online: 15 October 2018

(c) The Author(s) 2018. This article is published with open access

\begin{abstract}
Intratumoral electroporation-mediated IL-12 gene therapy (IT-pIL12/EP) has been shown to be safe and effective in clinical trials, demonstrating systemic antitumor effects with local delivery of this potent cytokine. We recently optimized our IL-12 gene delivery platform to increase transgene expression and efficacy in preclinical models. Here we analyze the immunological changes induced with the new IT-pIL12/EP platform in both electroporated and distant, non-electroporated lesions. IT-pIL12/EP-treated tumors demonstrated rapid induction of IL-12-regulated pathways, as well as other cytokines and chemokines pathways, and upregulation of antigen presentation machinery. The distant tumors showed an increase in infiltrating lymphocytes and gene expression changes indicative of a de novo immune response in these untreated lesions. Flow cytometric analyses revealed a KLRG1 $1^{\text {hi }} \mathrm{CD}^{+}$effector T-cell population uniquely present in mice treated with ITpIL12/EP. Despite being highly activated, this population expressed diminished levels of PD-1 when re-exposed to antigen in the PD-L1-rich tumor. Other T-cell exhaustion markers appeared to be downregulated in concert, suggesting an orchestrated "armoring" of these effector T cells against T-cell checkpoints when primed in the presence of IL-12 in situ. These cells may represent an important mechanism by which local IL-12 gene therapy can induce a systemic antitumor immune response without the associated toxicity of systemic IL-12 exposure.
\end{abstract}

\section{Introduction}

Interleukin 12 (IL-12) is pleotropic inflammatory cytokine, which links innate and adaptive immunity and drives Th1/ Tc1 cell-mediated immune responses. IL-12, therefore, would be a good candidate for increasing tumor immunogenicity. However, systemic administration of recombinant IL-12 protein [1-3] or IL-12-expressing adoptive cell

These authors contributed equally: Anandaroop Mukhopadhyay, Jocelyn Wright, Shawna Shirley.

Electronic supplementary material The online version of this article (https://doi.org/10.1038/s41434-018-0044-5) contains supplementary material, which is available to authorized users.

Robert H. Pierce

rpierce@fredhutch.org

1 OncoSec Medical Incorporated, 3565 General Atomics Court \#100, San Diego, CA 92121, USA

2 Fred Hutchinson Cancer Center, 1100 Fairview Avenue N, Seattle, WA 98109, USA therapies [4] have led to severe immune-related toxicities in patients. As an alternative, intratumoral (IT) gene therapy with plasmids expressing IL-12 has been tested both in experimental mouse models and in the clinic. As a monotherapy in advanced melanoma, IT electroporationmediated transfection of a plasmid encoding human IL-12 yielded a $33 \%$ best overall response rate, with $50 \%$ of patients showing regression of untreated lesions, without any reported systemic drug-related toxicity $[5,6]$.

In mouse models, previous studies have shown that IL12 introduced IT reduces tumor burden and prolongs survival [7-14]. In addition to reducing growth of treated tumors, IT IL-12 treatment induces a memory response, which protects mice from tumor re-challenge [7, 8, 11, 12], as well as reducing growth of metastases [8, 9] and untreated distant tumors [7, 12]. Effects of IT treatment with IL-12 on IT immunogenicity include local influx of $\mathrm{CD}^{+}$ $\mathrm{T}$ cells, production of interferon- $\gamma$ (IFN $\gamma$ ), and resultant increase in major histocompatibility complex (MHC) class I expression in treated tumors [7, 13]. General increase in infiltrating lymphocytes and reduction in tumor vascularity have also been noted in treated lesions [8]. Dissemination of 
tumor antigen-associated (TAA) $\mathrm{CD}^{+} \mathrm{T}$ cells with IT IL12 have been reported and depletion of $\mathrm{CD}^{+} \mathrm{T}$ cells diminished IL-12 antitumor effects, whereas $\mathrm{CD} 4^{+}$or NK depletion had a modest effect [7]. These depletion studies indicate that IT IL-12 therapy-mediated tumor immunity is mediated, in large part by $\mathrm{CD}^{+} \mathrm{T}$ cells, and suggest that IT IL-12 treatment may function as an in situ vaccine through the induction of cell death-mediated antigen release in a pro-inflammatory, strongly Th1-biased tumor microenvironment (TME) [15].

Based on previous clinical and preclinical studies and our recent work demonstrating a dose-dependent effect of ITpIL12/EP, we optimized our therapy to maximize transgene expression through modifications to the plasmid and electroporation parameters, resulting in significant systemic tumor growth control with a single treatment [16]. The IL12 encoding plasmid contained the p 35 and $\mathrm{p} 40$ subunits of murine IL-12 expressed from a polycistronic message that utilizes the picornovirus exon-skipping motif, P2A. In addition to a novel plasmid design, the new IT-pIL12P2A/ EP platform uses a reduced electric field strength and increased pulse duration to enhance transfection efficiency [17]. Expression of transgenes were detected in nearly $10 \%$ of tumor cells, approaching the efficiency of viral transduction methods [16]. Robust expression of IL-12p70 protein was detected in the electroporated lesion (EL) but remained low in serum [16].

In this study, we explore the mechanism of action of ITpIL12P2A/EP using a two-tumor contralateral model, created by flank injection of B16F10 melanoma cells into syngeneic C57BL/6 mice with particular emphasis on understanding "abscopal" effects in distant non-treated lesions (contralateral tumor). We provide evidence that IT IL-12 treatment leads to induction of IL-12-regulated genes, other cytokine and chemokines pathways, as well as genes for enhanced antigen processing and presentation in the treated tumor. These localized IL-12-mediated effects led to the generation of systemic tumor immune responses, including a surge of $\mathrm{KLRG} 1{ }^{\text {hi }} \mathrm{CD}^{+}$effector $\mathrm{T}$ cells detected in the spleen and in contralateral, non-treated tumor-infiltrating lymphocytes (TILs). Interestingly, this systemic immune response is accompanied by induction of IFN $\gamma$-mediated adaptive immune resistance markers, despite significant growth control of the distant, contralateral tumor. The IL-12-driven KLRG $1{ }^{\mathrm{hi}} \mathrm{CD}^{+}$effector cells detected in the Programmed death-ligand 1 (PD-L1)rich contralateral TME had decreased expression of PD-1, as well as other cell surface exhaustion markers as compared with those in control animals. Our results suggest that CD8 T cells primed in the IL-12-treated TME may be, at least transiently, "armored" against multiple T-cell checkpoints, contributing to their fitness as antitumor cytotoxic T lymphocyte (CTL) and may represent a prominent mechanism by which local IT IL-12 gene therapy can deliver a safe and effective abscopal response.

\section{Results}

To study the mechanisms of action of the optimized ITpIL12/EP therapy on distant, untreated lesions, a two-tumor contralateral model previously described [16] was used. The poorly immunogenic B16F10 cell line (C57B1/6J mice) was implanted in the subcutis on opposite flanks, on the left $(1,000,000$ cells $)$ and on the right $(250,000$ cells). Ten days post implantation, left tumors were electroporated once after injection with pIL12P2A (IT-pIL12P2A/EP) or empty vector (IT-pUMVC3/EP). As a control, some tumor-bearing mice were left untreated. Mice receiving IT-pIL12/EP (ITpIL12P2A/EP) demonstrated significantly reduced growth of the EL, as well as untreated lesions by day 6 as compared with control groups (Fig. 1). A slight growth delay in the EL was observed in the empty vector-treated mice as compared with untreated mice, however, no effect on the distant, contralateral tumors was observed.

\section{Gene expression changes in the TME of IT-IL-12-EP- treated tumors}

Seven days after EP, treated tumors were excised and total RNA was prepared from the tumor tissue. The transcriptional status of immune-related genes was assessed using the NanoString ${ }^{\circledR}$ nCounter platform. Hierarchical agglomerative clustering of 561 immune-related genes showed robust clustering of mice receiving IT-pIL12/EP (6/9 mice; Fig. 2a) indicating a strong IL-12-mediated modulation of the transcriptional status of immune genes in the treated B16F10 TME. An increase in transcripts associated with T lymphocytes $(C d 3, C d 4, C d 8)$, as well as myeloid-lineage cells (Cd11b, Cd11c, Emrl, Cd14; Figure S1b) in IT-pIL12/ EP-treated tumors were seen. Treated tumors were also analyzed morphologically by hematoxylin and eosin (H\&E) staining of formalin-fixed, paraffin-embedded sections at this time point, revealing extensive tissue necrosis, in association with IT hemorrhage and a marked pleomorphic inflammatory infiltrate, particularly pronounced at the margin of the tumor (Figure S1a). Focal, small areas of tumor necrosis were identified in tumors treated with ITpUMVC3/EP, but the extent of necrosis and the presence of hemorrhage and an associated inflammatory response were far diminished in comparison.

Many of IL-12 pleotropic pro-inflammatory effects, in particular, the generation of downstream antitumor cytotoxic T-cell responses, have been shown to be dependent on the downstream production of IFN- $\gamma[18,19]$. B16F10 tumors directly electroporated with pIL12 demonstrated a 
a

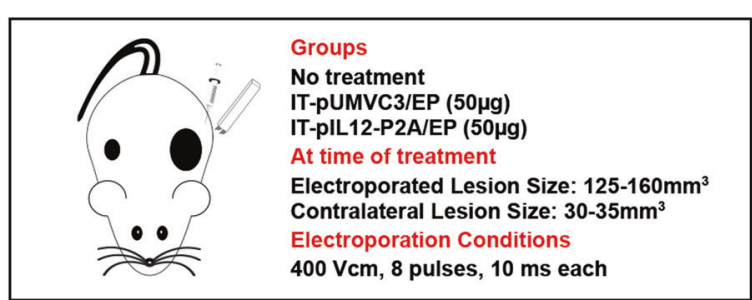

b
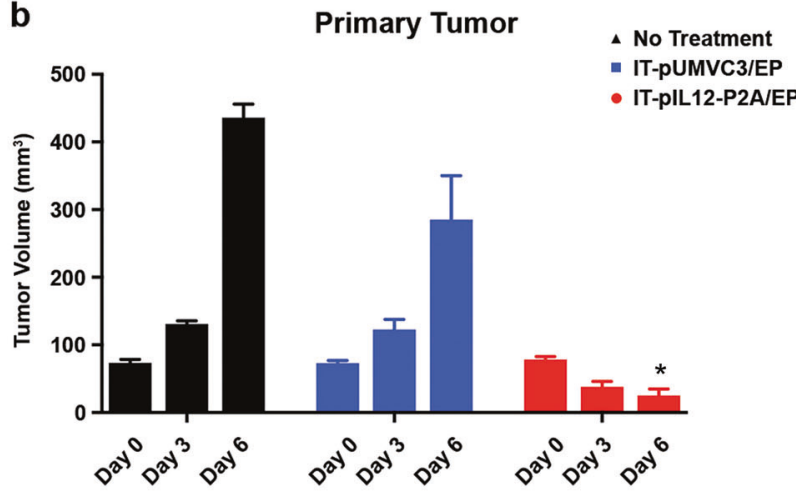

C Contralateral Tumor

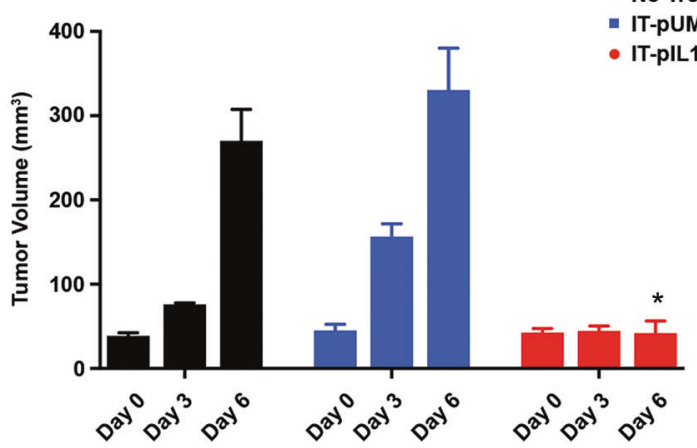

Fig. 1 IT-pIL12/EP led to tumor regression in a B16F10 contralateral tumor model. a Schematic of a two-tumor contralateral model; $\mathrm{B} 16 \mathrm{~F} 10$ or B16F10-OVA cells were implanted on both flanks of C57B1/6J 6- to 8-week-old female mice at different densities (1 million cells on left flank and 0.25 million cells on the right). Tumor (125-160 $\mathrm{mm}^{3}$ ) on left flank was electroporated, whereas the tumor $\left(30-35 \mathrm{~mm}^{3}\right)$ on the right flank (distant contralateral lesion) was left untreated. Treatment groups include IT injection of $50 \mu \mathrm{g}$ of empty vector plasmid control (pUMVC3) or $50 \mu \mathrm{g}$ of pIL12-P2A plasmid or untreated (no DNA or EP). b Growth of primary (electroporated) and $\mathbf{c}$ contralateral B16F10 lesions after IT-pIL12/EP (red) and IT-pUMVC3/EP (blue) and no treatment (black) are shown. Six days post treatment for both electroporated and contralateral tumors $(n=5$; statistical significance determined using two-way ANOVA with Bonferroni correction, ${ }^{*} p<0.0001$ ). IT-EP treatment was performed once on day 0 . Measurements for day 0 (pretreatment), and day 3 and 6 (post treatment) are shown. At 6 days post treatment, both electroporated and contralateral tumors from the IT-pIL12/EP cohort were significantly smaller ( $n=5$; statistical significance determined using two-way ANOVA with Bonferroni correction, $\left.{ }^{*} p<0.0001\right)$ (color figure online)

robust gene signature suggestive of IFN- $\gamma$ activation as expected (Figure S1c). Given the role of IFN- $\gamma$ in modulating genes involved in antigen processing and presentation machinery (APM), we investigated expression of transcripts associated with APM. IT-pIL12/EP led to a significant upregulation of multiple genes associated with antigen presentation on both MHC class I ( H2-Kb, Tapl, Tapbp, Psmb9/10, B2m) and MHC class II (H2-Aa, Ciita, $C d 74$ ) receptors (Fig. 2b).

Two transcription factors, Blimp-1 and T-bet, known to be regulated by IL-12 receptor signaling [20, 21], and important regulators of T-cell homeostasis, were induced 5-fold and 10fold, respectively, in the treated TME with IT-pIL12/EP as compared with control mice (Fig. 2c). In addition, tumors electroporated with IL-12 were enriched for genes involved in T-cell activation as determined by pathway scores using nSolver analysis software (Fig. 2c). Pathway scores generated with nSolver also demonstrated an upregulation of genes involved in the Janus kinase/signal transducers and activators of transcription (JAK/STAT) pathway specifically in the ITIL-12-EP group at day 7 (data not shown). As activation of this pathway is a direct downstream event in IL-12 signaling [22], we investigated the kinetics of enrichment of this gene signature (JAK/STAT).

In a separate experiment, treated tumors were excised 72 $\mathrm{h}$ after treatment and a NanoString ${ }^{\circledR}$ nCounter platform analysis was performed with the same immune-related gene panel. Significant clustering of IT-pIL12/EP-treated mice was observed (5/5 mice, data not shown). Genes involved in the JAK/STAT pathway were already significantly upregulated at $72 \mathrm{~h}$ in the IT-IL-12-EP group (Figure S2a). Furthermore, several immunostimulatory cytokines and chemokines involved in tumor inflammation were also upregulated in the IT-pIL12/EP group $72 \mathrm{~h}$ post EP (Figure S2b). Chemokines function in the recruitment of leukocytes important for both innate and adaptive immune responses. An upregulation of genes involved in activation of an innate response was observed in the IT-IL-12 EP groups at $72 \mathrm{~h}$ (Figure S2c) and remained high 7 days post EP (data not shown). An upregulation of other genes involved in inflammation were also observed early in tumors electroporated with IL-12 (Figure S2d). The striking upregulation of diverse inflammatory gene expression signatures (Fig. 2, S1, and S2) together with substantial tumor necrosis, hemorrhage and robust inflammatory infiltrate (Figures S3) illustrate that all of the components are present to suggest IT-pIL12P-EP functions as an in situ vaccine, leading to immunogenic tumor cell death and priming of a de novo adaptive immune response.

\section{IT-pIL12/EP increased tumor lymphocyte infiltration and markers for adaptive immune resistance in distant, contralateral lesions}

IT-pIL12/EP slowed the growth of distant, contralateral lesions significantly more than the empty vector group 


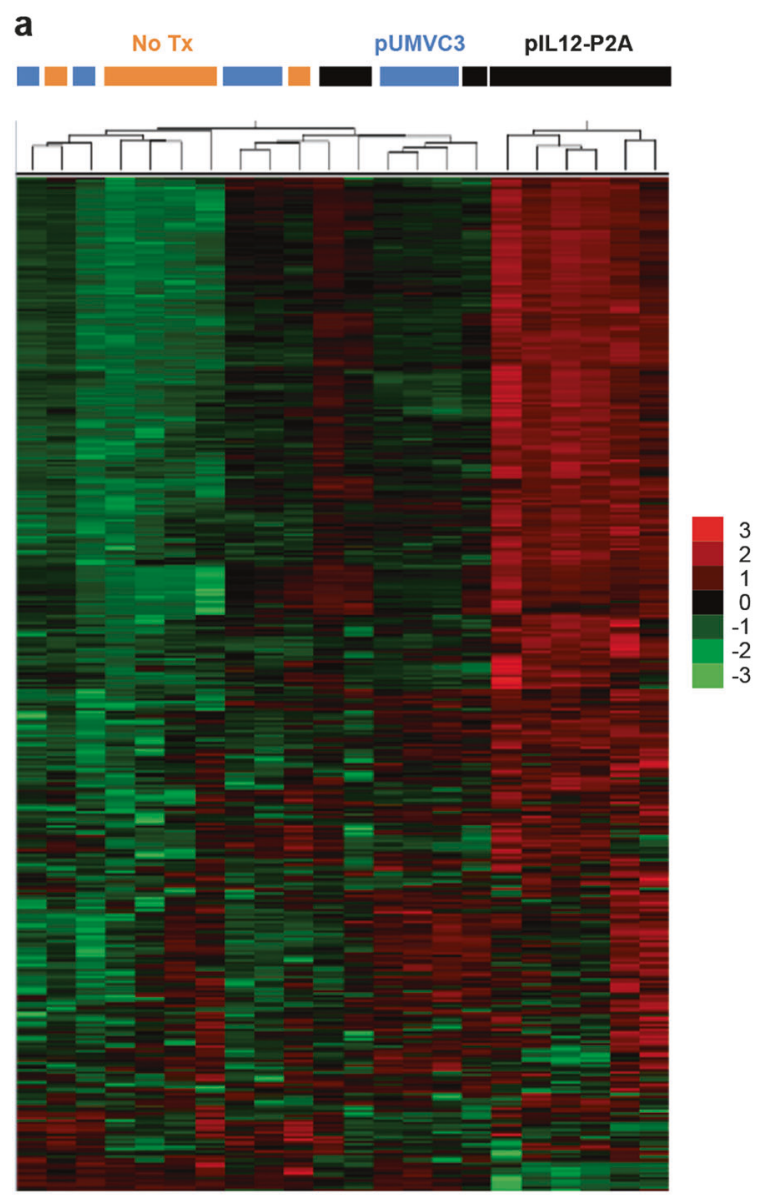

b
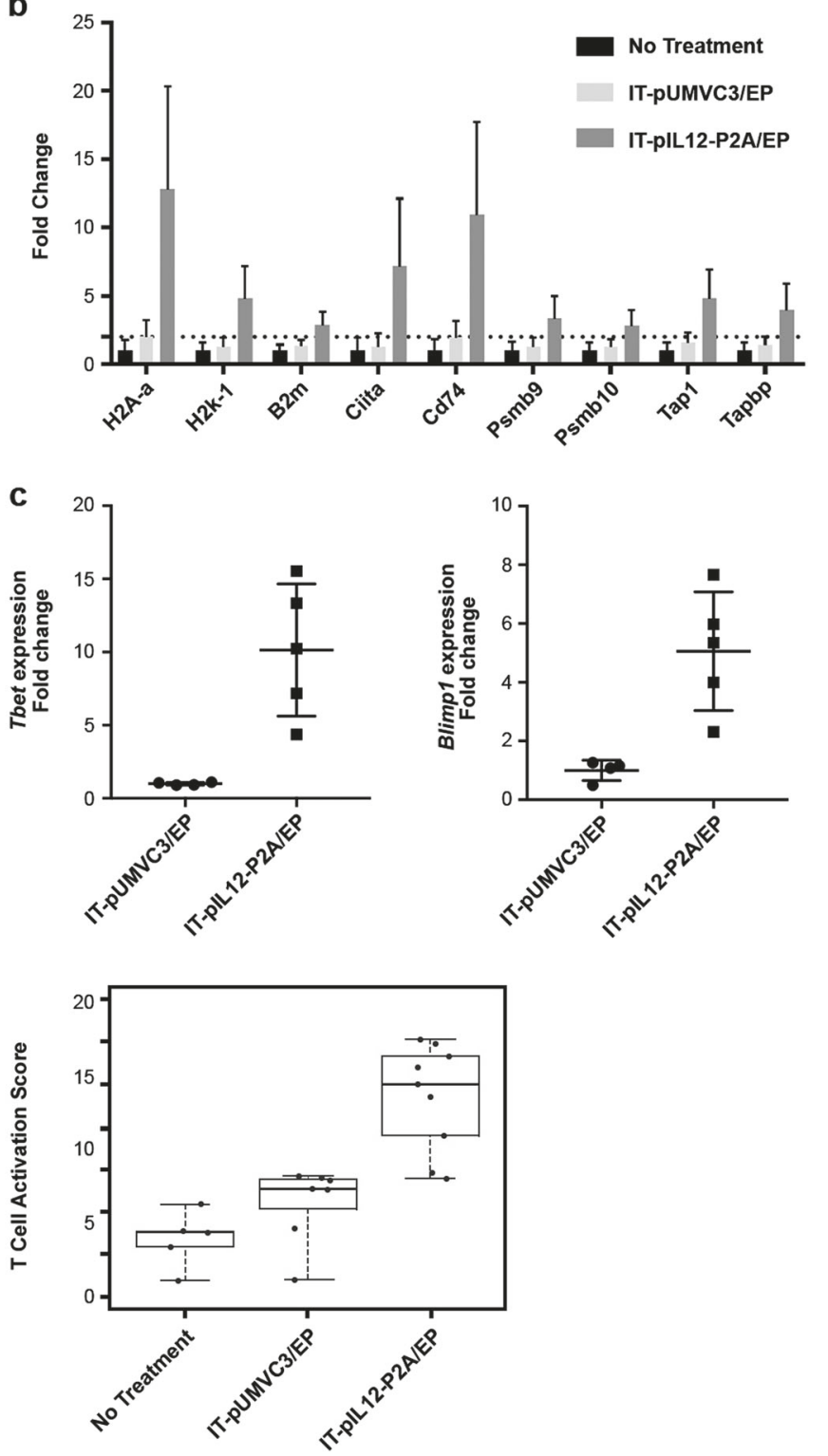

Fig. 2 IT-pIL12/EP induced conversion to a pro-immunogenic microenvironment in treated tumors. a Gene expression changes 7 days post treatment in electroporated B16F10 lesions assessed by NanoString ${ }^{\oplus}$ nCounter technology. Treatment groups were IT-EP of $50 \mu \mathrm{g}$ of empty vector plasmid (pUMVC3) or of $50 \mu \mathrm{g}$ of pIL12-P2A plasmid, as well as no treatment control mice. Hierarchical clustering and heat map ( $\mathrm{Z}$ scores) representation of all genes. Significant clustering of 6/9 mice receiving pIL12-P2A (black bar) was observed. Untreated (no Tx, orange bar) and empty vector plasmid (pUMVC3, blue bar) treated samples did not cluster suggesting no significant difference between the groups ( $n=9$ for pIL12-P2A, $n=7$ for pUMVC $3, n=6$ for untreated). b Induction in expression of APM genes, expressed as a fold change over no treatment levels at 7 days post treatment as assessed by nCounter technology (all genes

after a single treatment [16] (Fig. 1b). Seven days after treatment of tumors as described above, the contralateral tumors were excised and total RNA was prepared. Changes in gene expression were measured using the presented were statistically different from controls (untreated tumors); $p<0.05$, Holm-Sidak method). The dotted line represents a twofold increase over untreated tumor controls. c Top panel: fold change in Blimp1 and Tbet gene expression 7 days post treatment in mice receiving pIL12 ( $n=5$ for IL-12-P2A, black squares) compared with empty vector plasmid ( $n=4$ for pUMVC3, black circles). Statistical significance was calculated using $T$-test $(p<0.01)$. Bottom panel: enrichment of genes involved in T-cell activation 7 days post treatment represented as 'Pathway scores' determined by nSolver data analysis software. Pathway scores follow the assumptions of equal variance and normal distribution of $\mathrm{t}$ scores. The T-cell activation score in IL-12P2A group $(n=9)$ was significantly higher than the pUMVC3 $(n=7)$ and untreated group $(n=6)(p<0.0001$, one-way ANOVA) (color figure online)

NanoString ${ }^{\infty}$ Counter platform to investigate the mechanisms of growth inhibition of these distant, untreated lesions. Hierarchical agglomerative clustering of 561 immune-related genes from these cohorts showed 
a

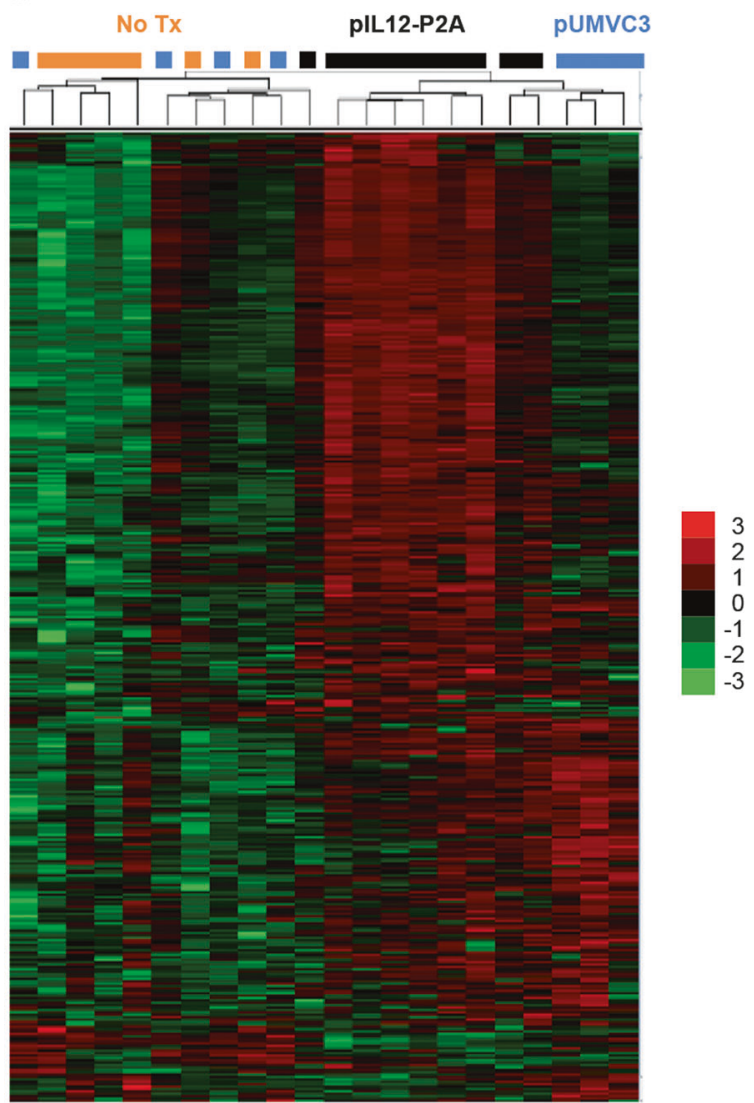

C
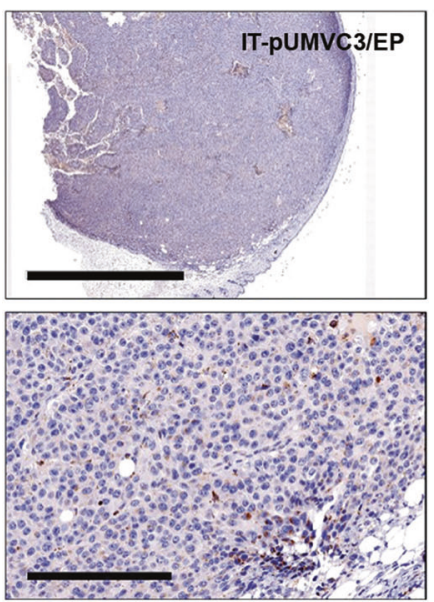
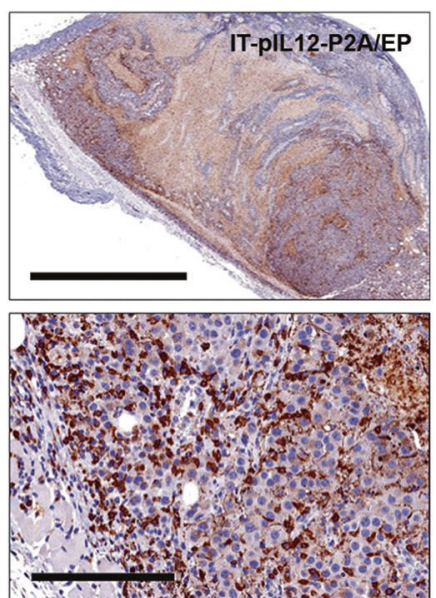

b
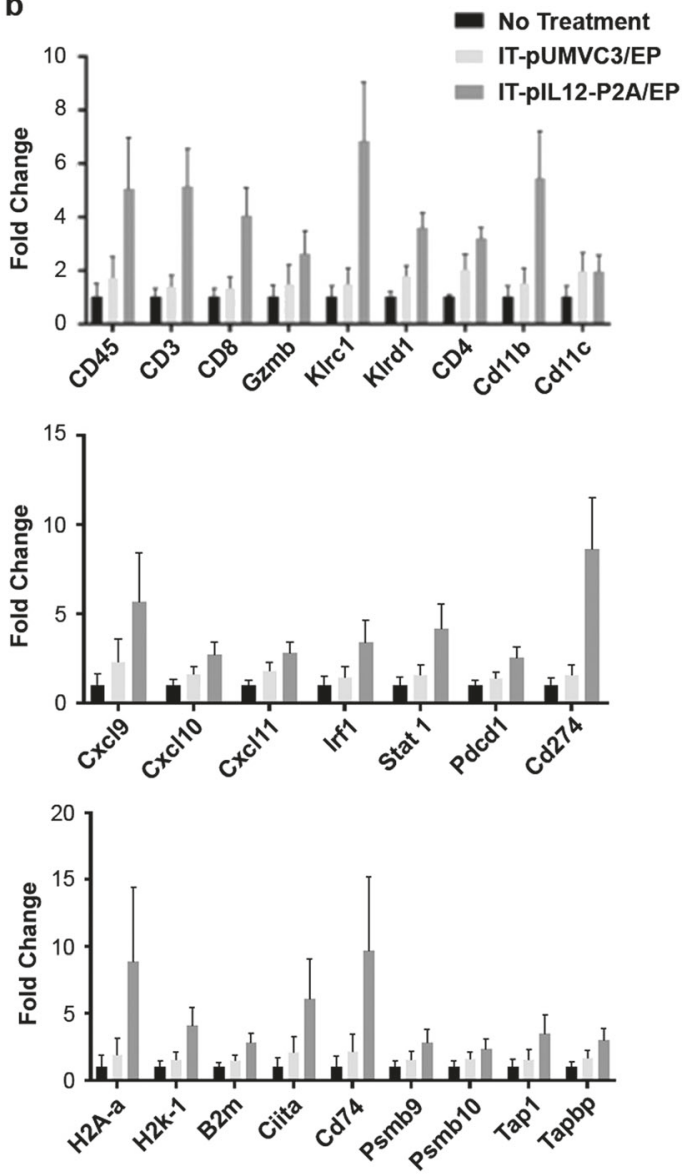

d

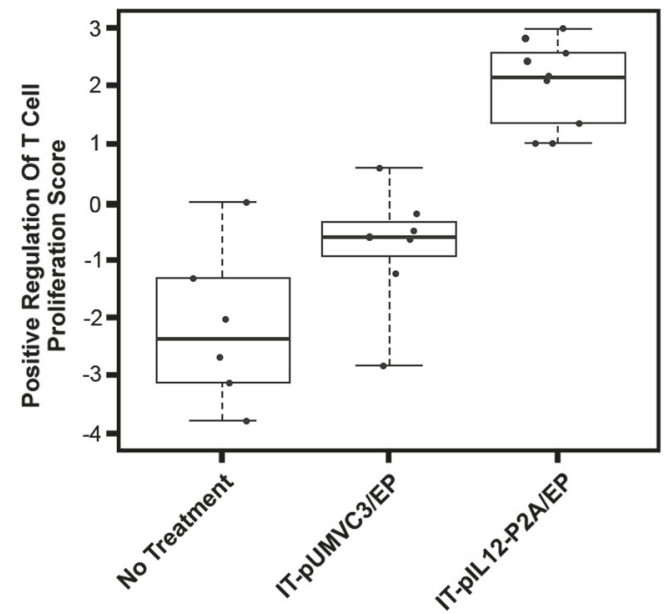

that mice whose primary tumors received IT-pIL12/EP clustered together (4/5 mice; Fig. 3a), indicating perturbations in gene expression in distant lesions mediated indirectly by IL-12 priming in treated tumors. Furthermore, the contralateral lesions from mice treated with ITpIL12/EP showed robust increases in transcripts associated with IFN- $\gamma$ signaling, T-cell activation, as well as those associated with lymphocytes and myeloid-lineage cells (Fig. 3b). Histochemical (H\&E) and immunohistochemical staining (anti-CD8a) of the distant, nonelectroporated distant tumors demonstrated the presence of a pronounced $\mathrm{CD} 8^{+} \mathrm{T}$-cell-rich inflammatory infiltrate in IT-pIL12/EP mice (Fig. 3c), which was relatively scant in control-treated mice, corroborating the observation of 
Fig. 3 IT-pIL12/EP increased TIL and led to adaptive immune resistance markers in contralateral tumors. Gene expression changes 7 days post treatment in contralateral $\mathrm{B} 16 \mathrm{~F} 10$ lesions. a Hierarchical clustering and heat map ( $\mathrm{Z}$ scores) representation of all genes is presented. Significant clustering of 6/9 mice receiving IT-pIL12-EP (black bar) was observed. Untreated (no Tx, orange bar) and empty vector plasmid (pUMVC3, blue bar) treated samples did not cluster respectively suggesting no significant difference between the groups ( $n=9$ for pIL12-P2A, $n=7$ for pUMVC3, $n=6$ for no Tx). b Induction in expression of markers for immune infiltrates (top panel), IFN- $\gamma$-responsive genes (middle panel) and APM-related genes (bottom panel), all expressed as a fold change compared with no treatment levels at 7 days post treatment as assessed by NanoString ${ }^{\circledR}$ Counter technology (all genes presented were statistically different from controls; $p<0.05$, Holm-Sidak method). c Immunohistochemical stain of murine CD8 protein (brown) in contralateral tumors at day 7 post EP (left: IT-pUMVC3/EP, right: IT-IL-12-EP). Low power scale bar $=2000 \mu \mathrm{m}$, High power scale bar $=200 \mu \mathrm{m}$. d Enrichment of genes involved in proliferation of $\mathrm{T}$ cells 7 days post treatment represented as 'Pathway scores' determined by nSolver data analysis software (NanoString"). Pathway scores follow the assumptions of equal variance and normal distribution of $t$ scores. The 'positive regulation of T-cell proliferation score' in IL-12-P2A group $(n=9)$ was significantly higher than the pUMVC3 $(n=7)$ and untreated group $(n=6)(p<0.0001$, one-way ANOVA) (color figure online)

increased $\mathrm{T}$ cells inferred based on gene expression of $C d 8 a, C d 3 e$ transcripts (shown in Fig. 3b). In addition, genes that are known to positively regulate $\mathrm{T}$-cell proliferation were also upregulated in IT-pIL12/EP mice (pathway score analysis, Fig. 3d) suggestive of a robust immune response. The induction of such a significant IFN- $\gamma$ signal in the distant, non-electroporated tumors suggests that $\mathrm{T}$ cells are engaging their cognate antigen in the contralateral TME, leading to local T-cell-mediated IFN- $\gamma$ production and downstream genes involved in adaptive immune resistance (e.g., PD-L1).

We previously demonstrated that IL-12p70 is detectable in IT-pIL12/EP-treated tumors but not significantly in serum using our new therapy platform [16]. To verify that the plasmid-derived IL-12 expression is not present in distant, contralateral lesions, we performed an enzymelinked immunosorbent assay (ELISA) on tumor tissue with an antibody directed against a P2A epitope that remains on the p35 subunit of plasmid-derived IL-12 cytokine. The treated and distant untreated tumors from mice were harvested $48 \mathrm{~h}$ after IT-pIL12/EP and ELISA performed on the tissue lysates. P2A antigen was detected in the electroporated tumors but not in distant, contralateral tumors (Figure S3) or in serum (data not shown), suggesting that IL-12p70-P2A protein translated from plasmids that were delivered by IT electroporation is largely confined to the treated tumor. Antitumor effects seen in distant contralateral lesions are therefore, likely mediated by changes in tumor immunity generated in the treated tumors or associated lymph nodes.

\section{IT-pIL12/EP led to systemic expansion of tumor- specific SIINFEKL tetramer ${ }^{+} \mathrm{CD8}^{+}$effector $\mathrm{T}$ cells}

To monitor IT-pIL12/EP generated tumor antigenspecific CD8 $\mathrm{T}$ cells, both systemically and in the contralateral TIL, we employed a B16F10 variant cell line, expressing the well-defined OVA antigen, containing the $\mathrm{K}^{\mathrm{b}}$-restricted CD8 epitope, SIINFEKL. IT-pIL12/EP controlled the growth of both electroporated and nonelectroporated B16F10-OVA tumors similar to what was seen in the B16F10 model (data not shown). To quantify the TAA CD8 (TAA-CD8 ${ }^{+}$) T cells, splenic lymphocytes were isolated from mice bearing B16F10-OVA tumors 8, 13, and 18 days post EP, stained with SIINFEKL tetramer and analyzed by flow cytometry. Enrichment of activated $\mathrm{CD}_{4}{ }^{+}, \quad$ SIINFEKL ${ }^{+} \mathrm{CD}^{+} \mathrm{T}$ cells was observed in the IT-pIL12/EP-treated group compared with IT-pUMVC3/EP-treated and untreated mice $(\sim 70$ fold; Fig. 4a), in agreement with a previous study showing IT-IL-12 induced dissemination of TAA-CD8 $+\mathrm{T}$ cells [7]. When examined over the time course, the elevated $\mathrm{TAA}^{-\mathrm{CD}} 8^{+} \mathrm{T}$-cell population persisted in the spleens of IL-12-treated mice for 18 days after treatment. A smaller number of TAA-CD ${ }^{+} \mathrm{T}$ cells were present at day 8 in control animals, but they were barely detectable at day 13 and day 18 time points, and not significantly different when compared with untreated (control) mice (Fig. 4a).

As measured on day 7 , these splenic SIINFEKL ${ }^{+} \mathrm{CD}^{+}$ $\mathrm{T}$ cells from IT-pIL12/EP-treated mice expressed significantly increased levels of the Ki-67 proliferation marker, as well as the cytotoxic T-cell marker, granzyme B (Figs. 4b, c), suggesting that this population represents effector $\mathrm{CD}^{+} \mathrm{T}$ cells $\left(\mathrm{T}^{\mathrm{eff}}\right)$. SIINFEKL ${ }^{+} \mathrm{T}^{\text {eff }}$ cells comprised $8.8 \%$ of total splenic $\mathrm{CD}^{+} \mathrm{T}$ cells (Fig. 4c). Of note, an enrichment of both $\mathrm{Ki}^{-} 67^{+}$and granzyme $\mathrm{B}^{+}$ CD8s were also observed in the SIINFEKL ${ }^{\mathrm{NEG}}$ population in the IT-pIL12/EP mice. These results suggest that ITpIL12/EP is driving the generation of antigen-specific CD8 $\mathrm{T}$ cells directed against other tumor-associated antigens, as well as the immunodominant SIINFEKL antigen.

In addition, the majority of splenic SIINFEKL ${ }^{+} \mathrm{CD}^{+}$ $\mathrm{T}$ cells from IT-pIL12/EP-treated mice had high expression of the KLRG1 cell surface marker (Fig. 5a, SIINFEKL ${ }^{+}$ cells shown in red). In contrast, in IT-pUMVC3/EP-treated mice, the few SIINFEKL ${ }^{+} \mathrm{CD}^{+} \mathrm{T}$ cells detected had much lower KLRG1 expression. Quantification of the percentage of SIINFEKL ${ }^{+}$and SIINFEKL ${ }^{\text {NEG }}$ CD8 T cells at day 8 that were KLRG $1^{\text {hi }}$ are shown in Fig. 5b. KLRG1, while ascribed various functions that are cell type and context dependent, is an effector T-cell marker [23] and known to be upregulated directly by IL-12 signaling [24]. We find 


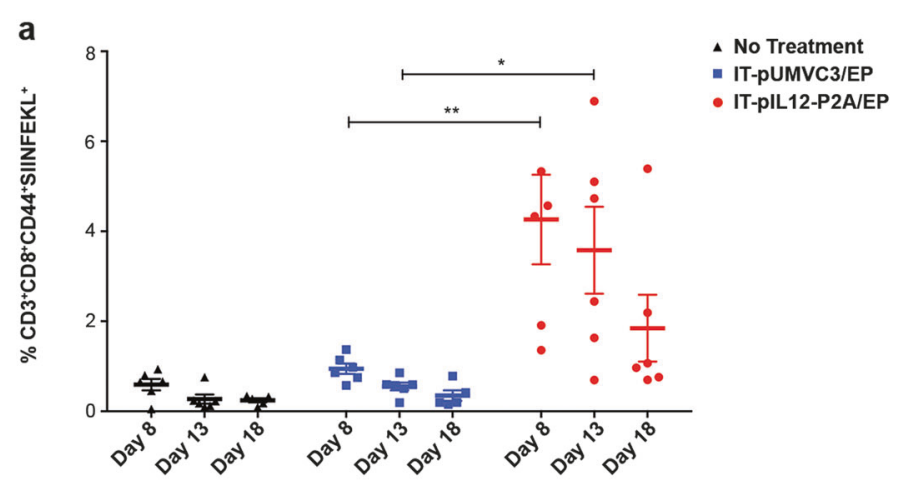

b
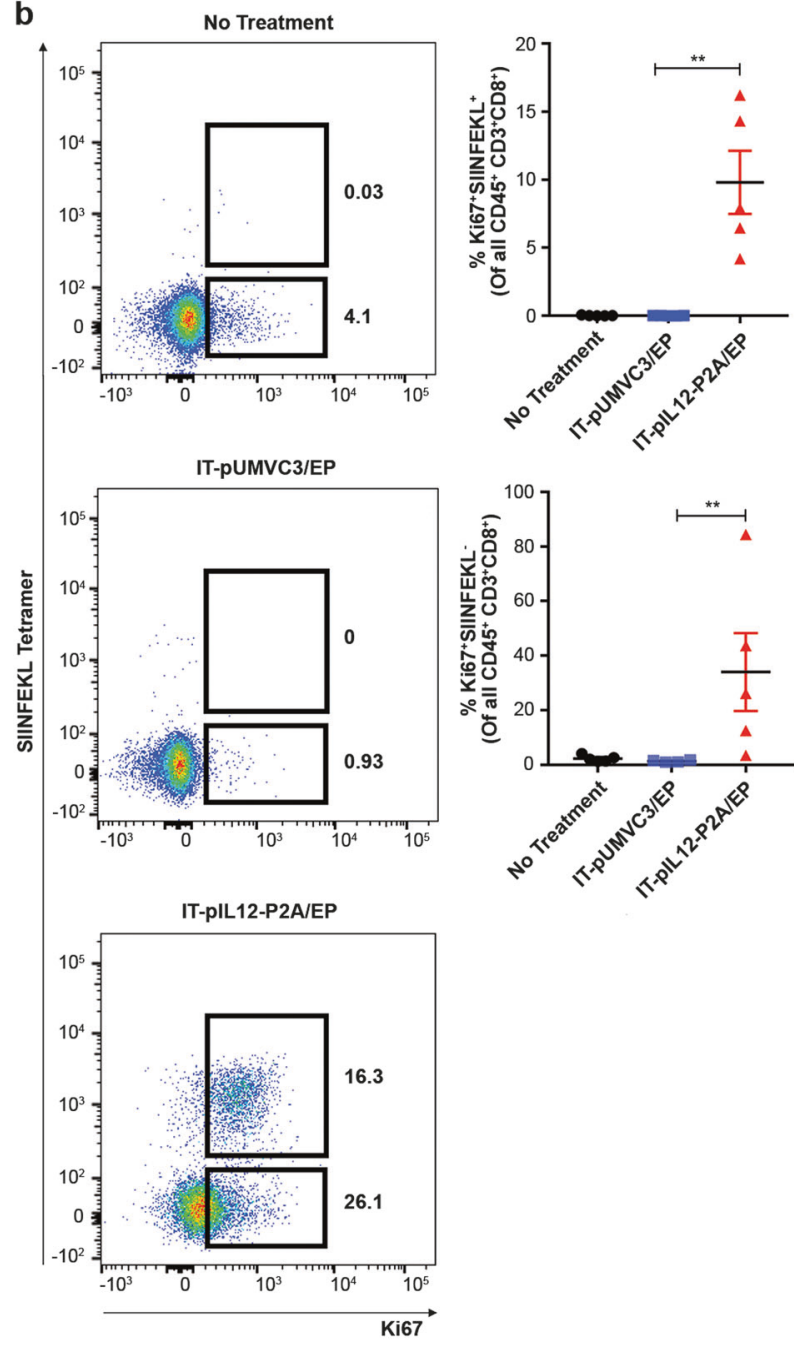

that KLRG1-positive CD8 cells were mostly all granzyme $\mathrm{B}(\sim 80 \%)$, as well as Ki-67-positive (Figure S4) thus suggesting the KLRG1-positive CD8+ $\mathrm{T}$ cells are potent effectors and are proliferating. Taken together, these data suggest that IT-pIL12/EP led to the significant expansion of a unique population of $\mathrm{KLRG} 1^{\mathrm{hi}} \mathrm{CD} 8^{+} \mathrm{TAA}-\mathrm{T}^{\text {eff }}$ cells that persist in the periphery longer than in control animals in this model. c
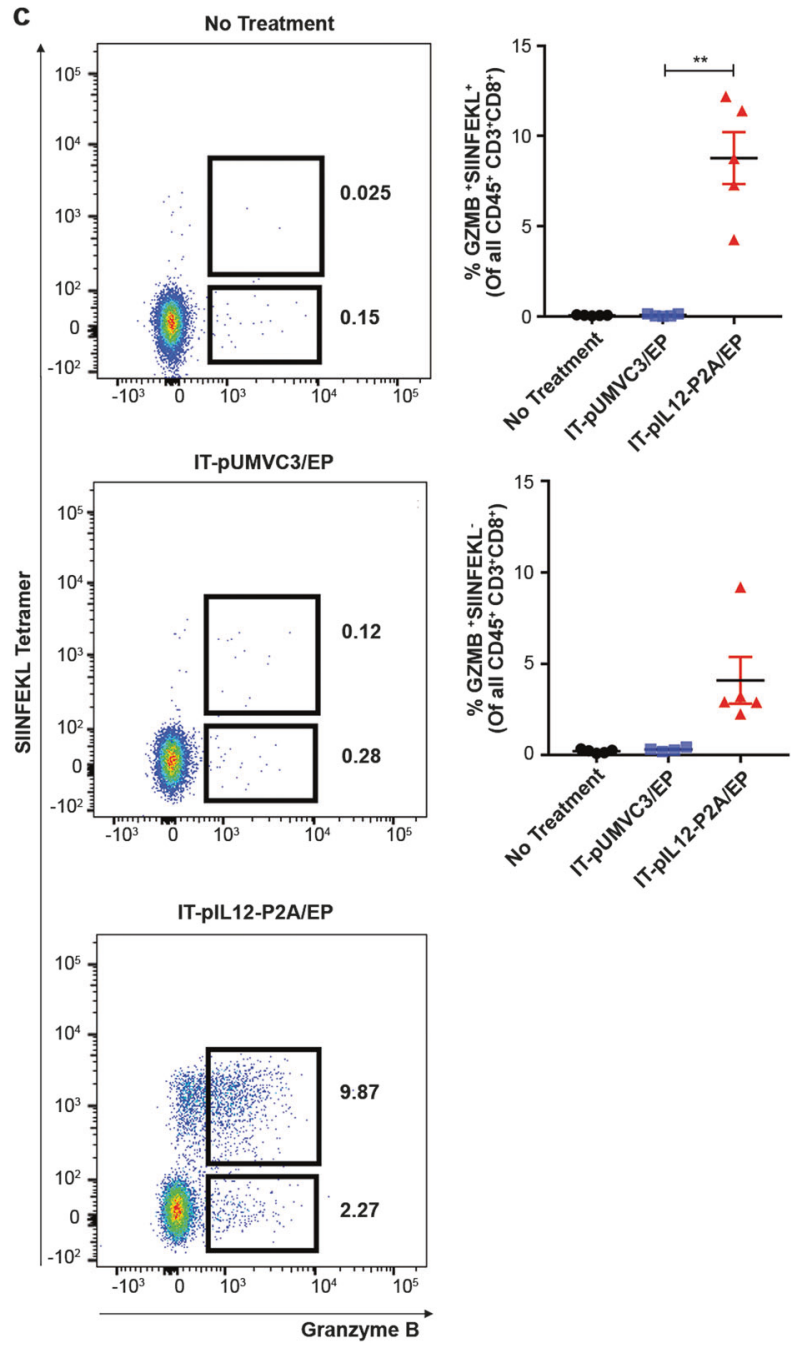

IT-pIL12/EP generated a unique TIL population of KLRG $1{ }^{\text {hi }} \mathrm{CD8}^{+} \mathrm{T}$ cells with diminished expression of multiple T-cell checkpoint proteins in distant, contralateral lesions

TILs were isolated from the contralateral B16F10-OVA tumors and analyzed by flow cytometry on days 8,13 , and 18 post EP. IT-pIL12/EP induced an increase in the number 
Fig. 4 Time course of flow cytometric analysis of splenocytes from mice treated with a single dose of IT-pIL12/EP therapy; persistence of TAA-CD ${ }^{+}$effector cells and enhanced expression of proliferation and cytotoxic markers. a Splenocytes were isolated 8, 13 and 18 days post EP from B16-OVA tumor-bearing mice intratumorally electroporated with pIL12P2A (red), pUMVC3 (blue) or left untreated (black) and analyzed by flow cytometry. Scatter plots show mean \pm SEM percentage of all LIVE splenocytes that were CD19 $9^{\mathrm{NEG}} / \mathrm{NK} 1.1^{\mathrm{NEG}} / \mathrm{CD} 3$ ${ }^{+} / \mathrm{CD}^{+} / \mathrm{CD} 44^{+} / \mathrm{SIINFEKL}$ tetramer ${ }^{+}$at each time point $(n=6$ mice per cohort per time point; total $n=18$ for each treatment group; $* * p<$ $0.01,{ }^{*} p<0.05$, individual $t$-test, Holm-Sidak method). Results presented were confirmed in two other independent electroporation experiments. b In a separate experiment, splenocytes were isolated 7 days post EP from B16-OVA tumor-bearing mice left untreated or intratumorally electroporated with pIL12-P2A or pUMVC3 control and analyzed by flow cytometry. Splenocytes were gated as follows prior to analysis: LIVE, CD $19^{\mathrm{NEG}} \mathrm{NK} 1.1^{\mathrm{NEG}} / \mathrm{CD} 3^{+} \mathrm{CD} 8^{+}$cells. Representative dot plots from one mouse per cohort show gating for Ki67 ${ }^{+}$SIINFEKL ${ }^{+} \mathrm{CD}^{+}$and $\mathrm{Ki}^{+} 7^{+}$SIINFEKL ${ }^{\mathrm{NEG}} \mathrm{CD}^{+}{ }^{+}$(left panels). Scatter plots show quantification $(\%)$ of $\mathrm{Ki} 67^{+} \mathrm{SIINFEKL}^{+}, \mathrm{Ki} 7^{+} \mathrm{SIINFEKL}^{\mathrm{NEG}}$ from all mice (right panels, $n=5$ per cohort ${ }^{*} p$-value $=0.009$, one-way ANOVA, Kruskal-Wallis test). c Splenocytes isolated 7 days post EP from B16-OVA tumor-bearing mice were gated as described in (b) and analyzed by flow cytometry. Representative dot plots show gating for granzyme $\mathrm{B}^{+}$SIINFEKL ${ }^{+} \mathrm{CD}^{+} \mathrm{T}$ and granzyme $\mathrm{B}^{+}$SIINFEKL${ }^{\mathrm{NEG}} \mathrm{CD}^{+} \mathrm{T}$ cells from one mouse per cohort (left panels). Scatter plots show quantification $(\%)$ of granzyme $\mathrm{B}^{+}$SIINFEKL $^{+}$and granzyme $\mathrm{B}^{+}$SIINFEKL ${ }^{\mathrm{NEG}} \mathrm{CD}^{+}{ }^{+}$cells from all mice (right panels, $n=5$ per cohort $* p$-value $=0.021$, one-way ANOVA, Kruskal-Wallis test). Results presented were repeated in two independent electroporation experiments (color figure online)

of total $\mathrm{CD}^{+} \mathrm{TIL}$ in these distant lesions, particularly at later time points, with little effect on the levels of $\mathrm{CD}^{+}$ $\mathrm{T}$ cells or regulatory $\mathrm{T}$ cells $\left(\mathrm{T}_{\text {reg }}\right)$ (Figure $\mathrm{S} 5$ ). We focused our analysis principally on the tumor antigen-specific SIINFEKL ${ }^{+} \mathrm{CD}^{+}{ }^{+}$TIL populations. On day 8 , SIINFEKL tetramer ${ }^{+} \mathrm{CD}^{+} \mathrm{T}$ cells were detected in the TIL from all treatment groups. Both IT-pIL12/EP and IT-pUMV3-EPtreated mice had higher levels of these cells than did the untreated control mice (Fig. 6a). However, by day 13, the SIINFEKL ${ }^{+} \mathrm{CD}^{+}$population diminished in control groups $(<1 \%$ of total TIL) but persisted in IL-12-treated animals $(\sim 7 \%)$.

When the SIINFEKL ${ }^{+} \mathrm{CD}^{+}$population detected in contralateral TIL from IT-pIL12/EP and IT-pUMV3-EPtreated mice at day 8 were compared for expression of PD1, IL-12-treated animals had a distinct cluster of PD- $1^{\text {lo }}$ cells (Fig. 6b; compare density plots from representative IL-12 vs. empty vector-treated animals). These results showed that, while both cohorts of animals had significant TAA$\mathrm{CD}^{+}$TIL at this time point, these cells differed in their expression of the cell surface PD-1 exhaustion marker. When the relative expression of both the KLRG1 and PD-1 cell surface markers were examined together in distant tumor TIL, The SIINFEKL ${ }^{+}$CD8 TIL from control (no treatment and IT-pUMVC3/EP-treated) mice showed a predominant unimodal population of KLRG $1{ }^{\mathrm{lo}} \mathrm{PD}-1^{\mathrm{hi}} \mathrm{CD} 8^{+}$ T cells (only IT-pUMVC3/EP is shown; Fig. 7a; circled in red). In sharp contrast, however, TIL from the IT-pIL12/EP group exhibited a population of KLRG $1^{\text {hi }} \mathrm{PD}-1^{\text {lo }}$ cells (blue circles), in addition to the baseline KLRG $1{ }^{10} \mathrm{PD}-1^{\text {hi }}$ population seen in empty vector-treated mice. This KLRG1 $1^{\text {hi }} \mathrm{PD}$ $1^{\text {lo }}$ population represented at least $30 \%$; Fig. 7 a) of the SIINFEKL ${ }^{+} \mathrm{CD}^{+}$TIL by day 13 and only emerged in response to IT-pIL12/EP treatment, suggesting that these TIL may be related to $\mathrm{T}^{\text {eff }}$ cells described previously in the spleen (see Figs. 4 and 5). The ratio of these two discrete SIINFEKL ${ }^{+}$CD 8 TIL populations (i.e., KLRG $1{ }^{\text {hi }} \mathrm{PD}-1 \%$ PD-1 ${ }^{\text {hi }}$ ) was increased in the IT-pIL12/EP mice compared with both untreated (no treatment) and IT-pUMVC3/EP control animals at all time points (Fig. 7b). Of interest, when a similar analysis was done on the SIINFEKL ${ }^{\mathrm{NEG}} \mathrm{CD} 8^{+} \mathrm{TIL}$, presumably directed against other tumor antigens, a smaller, yet significant increase in these KLRG $1{ }^{\text {hi }}$ PD- ${ }^{\text {lo }}$ TIL was seen (Figure S6). This distinct population of TIL present in IT-pIL12/EP-treated mice was detected at all three time points examined in this experiment, and was recapitulated in two other independent electroporation experiments (data not shown).

In order to better understand the significance of this lowlevel expression of PD- 1 on these antigen-specific KLRG $1^{\text {hi }}$ CD8 T cells, we analyzed the co-expression of CTLA-4 as high levels of PD- 1 and CTLA- 4 on TIL have been shown to identify exhausted $\mathrm{CD}^{+} \mathrm{T}$ cells in melanoma $[25,26]$. TIL from all groups of mice demonstrated a similar uniform population of PD- $1^{\text {hi }} \mathrm{CD} 8 \mathrm{~T}$ cells with significant percentage of high co-expression of CTLA-4, indicating the presence of a baseline exhausted tumor antigen-specific CD8 population. Only, however, in the IT-pIL12/EP-treated mice, was a distinct $\mathrm{PD}-1^{\mathrm{lo}} \mathrm{CTLA} 44^{\text {lo }} \mathrm{CD} 8$ population observed (Fig. 7c), which failed to upregulate PD-1 or CTLA-4 upon infiltration into the antigen-rich microenvironment of the contralateral tumor. The percentage of $\mathrm{T}$ cells that were PD- $1{ }^{\mathrm{lo}} \mathrm{CTLA} 4{ }^{\mathrm{lo}}$ was significantly higher in the IT-pIL12/EP-treated group as compared with both control groups (Fig. 7c, lower panels). Expression of TIM-3 and LAG-3 were found to parallel the unexpected expression patterns of CTLA-4 and PD-1 (Figure S7), suggesting a coordinated downregulation of these checkpoint proteins in the IT-pIL12/EP emergent KLRG1 ${ }^{\text {hi }} \mathrm{PD}-1^{\text {lo }} \mathrm{CD} 8^{+} \mathrm{TIL}$ population.

\section{Discussion}

In a Phase 1 clinical trial in advanced melanoma, EPmediated transfection of plasmid-encoded IL-12 was safe and led to local necrosis and inflammation in the electroporated tumor, as well as regression of distant untreated 

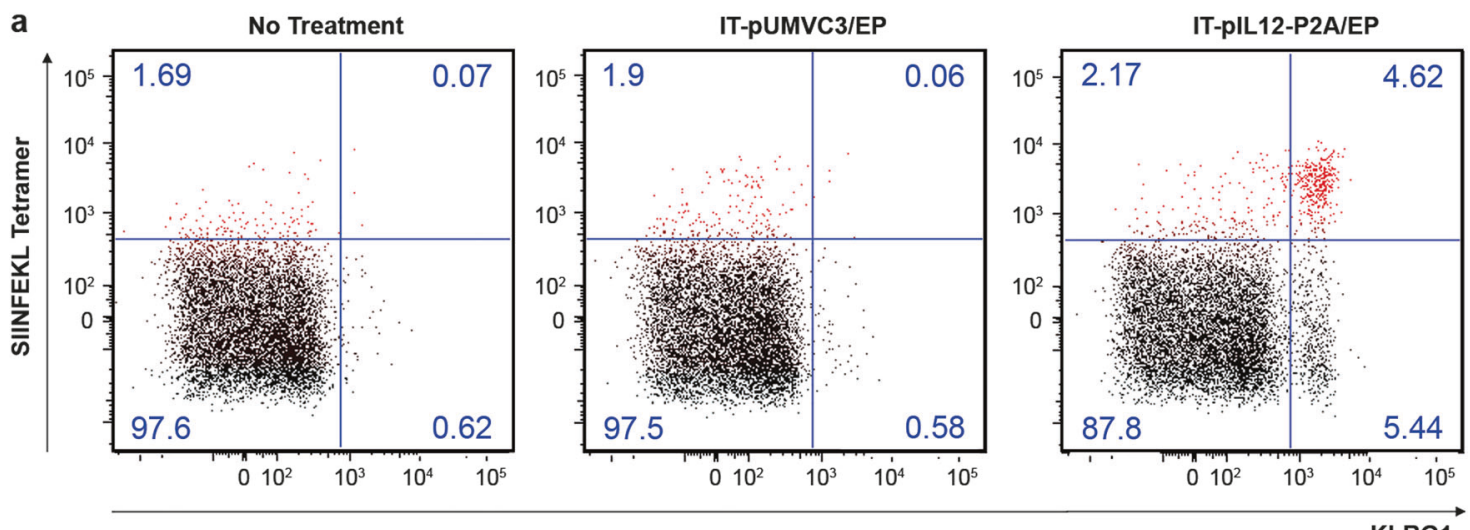

b
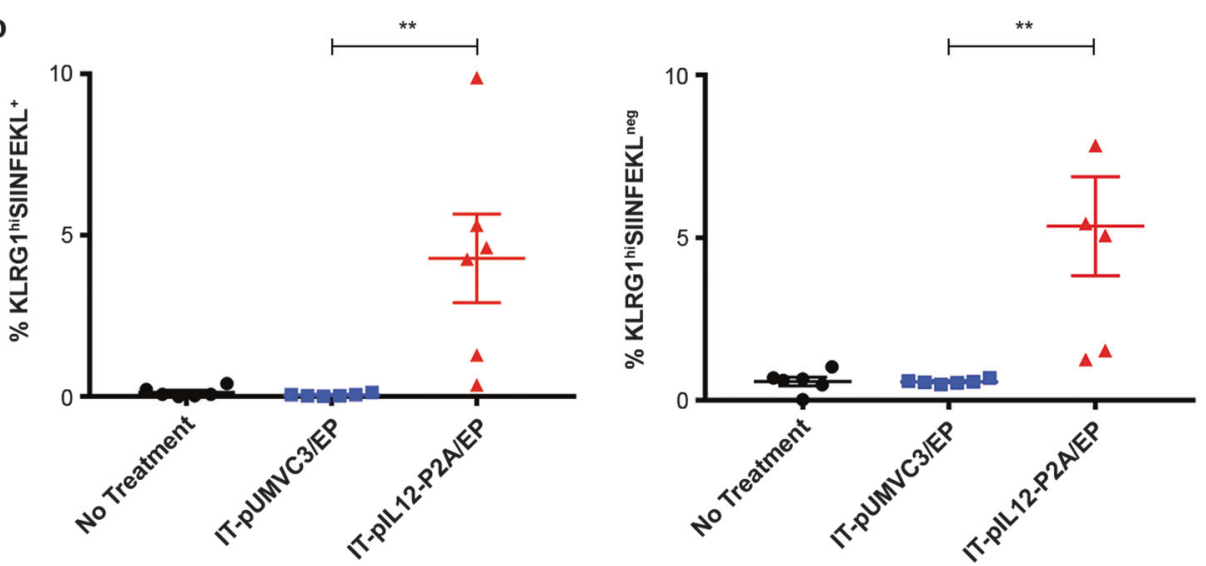

Fig. 5 IT-pIL12/EP enriched for a KLRG1 ${ }^{\text {hi }}$ subpopulation in splenocytes from mice bearing B16-OVA tumors. Splenocytes were isolated 8 days post EP from B16-OVA tumor-bearing mice intratumorally electroporated with pIL12-P2A or pUMVC3 or left untreated (no treatment) and analyzed by flow cytometry. a Dot plots for representative mice from the IT-pIL12/EP, the IT-pUMVC3/EP, and the no treatment cohorts show KLRG1 and SIINFEKL tetramer status of $\mathrm{CD}^{+}{ }^{+}$T cells; SIINFEKL ${ }^{\text {NEG }}$ cells are black and SIINFEKL ${ }^{+}$ cells are shown in red. Prior to the analysis shown, splenocytes were gated for $\mathrm{LIVE} / \mathrm{CD} 19^{\mathrm{NEG}} / \mathrm{NK} 1.1^{\mathrm{NEG}} / \mathrm{CD}^{+} / \mathrm{CD}^{+}$events. b Scatter

plots show quantification $(\%)$ of $\mathrm{KLRG}^{\mathrm{hi}}{ }^{\mathrm{SIINFEKL}}{ }^{+}$and KLRG $1^{\text {hi }}$ SIINFEKL ${ }^{\text {NEG }}$ CD8 $\mathrm{T}$ populations at day 8 for all mice (represents quantification of numbers in upper right and upper left quadrants of dot plots shown in (a), respectively). Both SIINFEKL ${ }^{+}$ and SIINFEKL ${ }^{\text {NEG }}$ CD8 lymphocytes were significantly enriched for KLRG1 ${ }^{\text {hi }}$ expression in IT-pIL12/EP mice compared with empty vector/EP ( $n=6$ per cohort; $* * p=0.004$, one-way ANOVA). Results presented were confirmed in two other independent electroporation experiments (color figure online)

lesions in some cases [5, 27]. Phase 2 clinical trials confirmed that IT delivery of IL-12 plasmid DNA by electroporation (Immunopulse ${ }^{\circledast}$ IL-12) induced objective responses including abscopal regressions of distant untreated lesions [27, 28]. However, only $10 \%$ of patients receiving IT-pIL12/EP show a complete therapeutic response. In a recently published paper [16], we demonstrated that improving electroporation parameters and expression of plasmid-derived IL-12p70 enhanced the systemic antitumor response with only a single treatment in mouse models. Higher IL-12 expression was achieved through both an improved plasmid design, as well as reduced voltage and increased pulse length, which led to increased IFN $\gamma$ and a higher $\mathrm{CD}^{+} / \mathrm{CD}^{+}{ }^{+}$-cell ratio with the tumor. Further, a dose-response tumor regression data suggested that an increase in IL-12 expression increased efficacy [16].

Using a two-tumor murine model, we explored the mechanism of action of the new IT-pIL12/EP platform, particularly the IT-pIL12/EP-mediated perturbations of distant non-treated contralateral tumors. In the low TIL B16F10 two-tumor mouse model, regression of the treated lesion was associated with rapid induction of IL-12regulated pathways, as well as upregulation of cytokines, chemokines and antigen presentation pathways (Fig. 2). An increased influx of lymphocytes and dramatic changes in gene expression consistent with strong inflammatory response in the distant, contralateral lesions indicated a strong abscopal response in IT-pIL12/EP-treated mice (Fig. 3).

B16F10 tumors, like most cutaneous melanomas arising in patients, have a relatively large mutational load with a correspondingly high prevalence of predicted neoantigens [29]. The poor immunogenicity of the B16F10 mouse tumor 


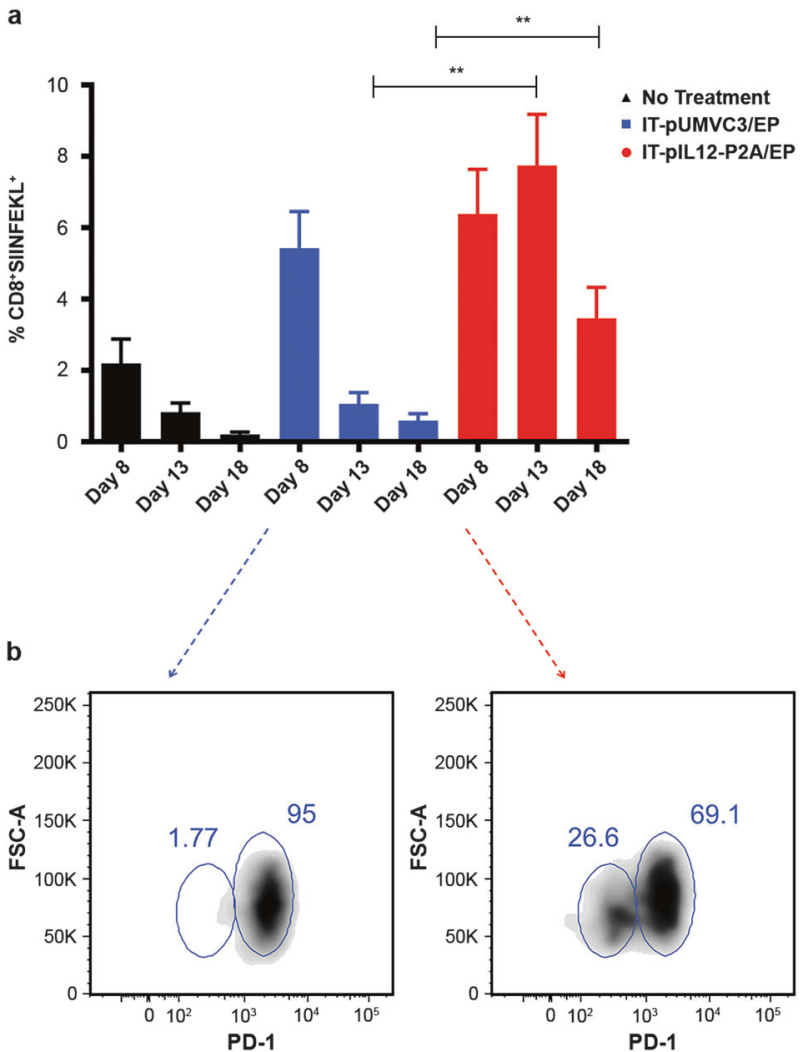

Fig. 6 Analysis of tumor-infiltrating lymphocytes (TILs) present in untreated tumors over time; persistence of SIINFEKL ${ }^{+} \mathrm{CD} 8^{+} \mathrm{T}$ cells in IT-pIL12/EP-treated mice. Lymphocyte fraction of cells isolated from excised tumors were stained with SIINFEKL tetramers and other lymphocyte markers and analyzed by flow cytometry. Prior to analysis shown, tumor cells were gated for LIVE/CD $19^{\mathrm{NEG}} / \mathrm{NK} 1.1^{\mathrm{NEG}} / \mathrm{CD}^{+} /$ $\mathrm{CD}^{+}$events. a Bars in graph shown represent the mean \pm SEM percentage of $\mathrm{CD}^{+}$TIL that were SIINFEKL tetramer ${ }^{+}$at 8,13 , and 18 days after IT-pIL12/EP (red) or IT-pUMVC3/EP (blue) treatment of tumors on the opposite flank. Tumors from untreated mice (black) are shown for comparison; $(n=6$ mice per cohort per time point; total $n=18$ for each treatment group; $* * p=0.0022$ for day 13 and 0.0043 for day 18, Mann-Whitney test). b Density plots showing PD-1 staining $(x$ axis) vs. forward scatter area (FSC-A; $y$ axis) of SIINFEKL ${ }^{+} \mathrm{CD}^{+} \mathrm{CD}^{+}$TIL from the untreated tumors of representative mice on day 8 from IT-pIL12/EP (right) and IT-pUMVC3/EP (left) treated cohorts to illustrate PD- ${ }^{10}$ satellite population detectable in IT-pIL12/EP-treated mice (color figure online)

model has been attributed to a lack of effective antigen presentation due to epigenetic suppression of APM, including MHC Class I, MHC Class II and Tap-1 [30]. IFN$\gamma$ exposure is known to potently reverse this methylationdependent epigenetic suppression of APM [31]. In this study, we show that IT-pIL12/EP led to an increase in IFN$\gamma$ in treated tumors, similar to previous reports [7, 14], and further analyze IFN- $\gamma$-responsive genes involved in antigen processing and presentation in treated lesions (Fig. 2). Previously, Restifo and colleagues [32] elegantly demonstrated that IL-12 delivered IT to B16F10 tumors using transgenic pmel $\mathrm{CD} 8 \mathrm{~T}$ cells led to similar IFN- $\gamma$ upregulation of APM and converted abundant IT myeloidderived suppressor cells into cross-presenting APCs. Thus, IT-pIL12/EP may be acting like an in situ vaccine [15], resulting in the induction of immunogenic cell death, uptake of tumor-associated antigens by APCs in the appropriate pro-inflammatory milieu to enhance immunogenic crosspresentation.

Using a two-tumor model with a B16F10 cell line variant expressing a traceable antigen, we show that IT-pIL12/EP resulted in dissemination of tumor antigen directed (SIINFEKL tetramer positive) CD8 $\mathrm{T}$ cells in the spleen that persisted for up to 18 days after a single treatment (Fig. 4a). In addition, a significant enrichment of splenic SIINFEKL ${ }^{+}$ CD8 $\mathrm{T}$ cells that expressed effector $\mathrm{T}$-cell markers $\left(\mathrm{GRZMB}^{+}\right.$or Ki-67 ${ }^{+}$) was detected (Figs. 4b, c). Furthermore, the IT-pIL12/EP-dependent SIINFEKL ${ }^{+} \mathrm{T}^{\text {eff }}$ population in the spleen was found to be predominantly KLRG1 $1^{\text {hi }}$ (Fig. 5 and S4). In addition to the SIINFEKL ${ }^{+}$splenocytes, we found a significant number of SIINFEKL ${ }^{\text {NEG }}$ granzyme $\mathrm{B}^{+}$(Fig. 4) and SIINFEKL ${ }^{\mathrm{NEG}} \mathrm{KLRG}^{+}$(Fig. 5) $\mathrm{CD}^{+}$ $\mathrm{T}$ cells suggesting that IT-pIL12/EP also induced effector Tcell directed against other endogenous B16F10 antigens [29]. We also note a similar SIINFEKL ${ }^{\text {NEG }}$ population in contralateral tumor TIL (Figure S6).

In a previous study, Sin and co-workers demonstrated that IT electroporation in B16F10 tumors induced systemic CD8 T-cell responses directed against a known endogenous B16F10 antigen (Trp2180-188 epitope) and generated therapeutic effects against distant, contralateral tumors [7]. They further show that pretreatment of mice with anti-CD8 antibodies significantly reduced the efficacy of the IL-12/EP therapy thus demonstrating the importance of the CD8 Tcell response. Our study complements and extends these observations by further characterizing $\mathrm{TAA}^{-\mathrm{CD}} 8^{+}$cells within the, distant, contralateral tumors. Taken together with the work of Sin et al., our studies strongly suggest that IL-12 treatment generates and disseminates TAA-CD8 ${ }^{+}$ cells that participate in the antitumor response in distant, contralateral tumors.

Strong IL-12 signaling during T-cell priming has been implicated in the generation of $\mathrm{KLRG}^{+}$effector CD8 $\mathrm{T}$ cells through upregulation of the transcription factor T-bet [24] and can lead to increased longevity of these cells in vivo upon adoptive transfer [33-35]. Other studies attribute optimal differentiation into effector $\mathrm{CD} 8 \mathrm{~T}$ cells to Blimp-1 and T-bet, both IL-12-driven nuclear transcription factors [21]. Consistent with these reports, transcripts for both T-bet and Blimp- 1 genes were upregulated in the ITpIL12/EP-treated lesions (Fig. 2) and significant KLRG1 expression on $\mathrm{CD} 8^{+} \mathrm{T}$ cells was only present in IT-pIL12/ EP mice, Furthermore, KLRG $1{ }^{\text {hi }} \mathrm{CD} 8 \mathrm{~T}$ cells were detected in the spleen for up to 18 days. In our model, KLRG1 expression seems to serve as a useful phenotypic biomarker 
a
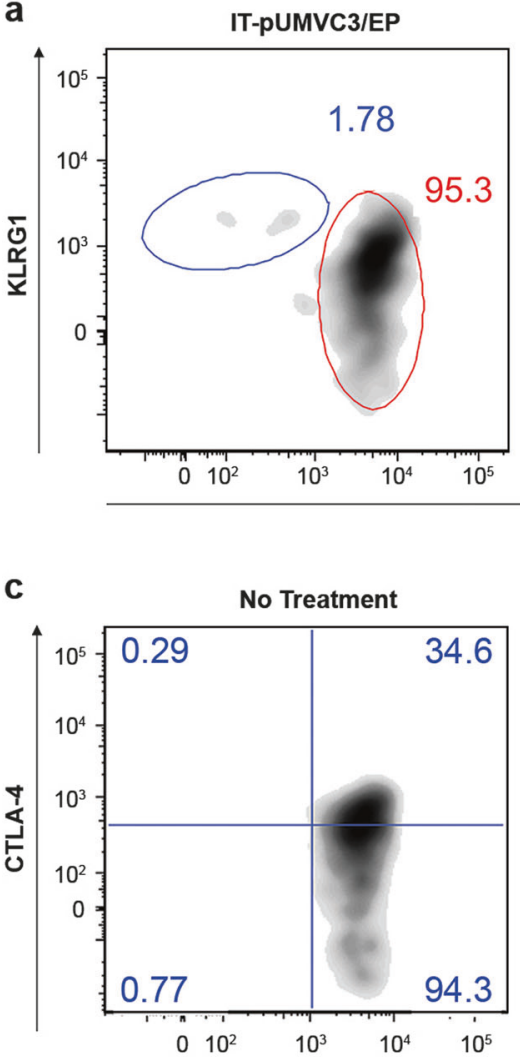

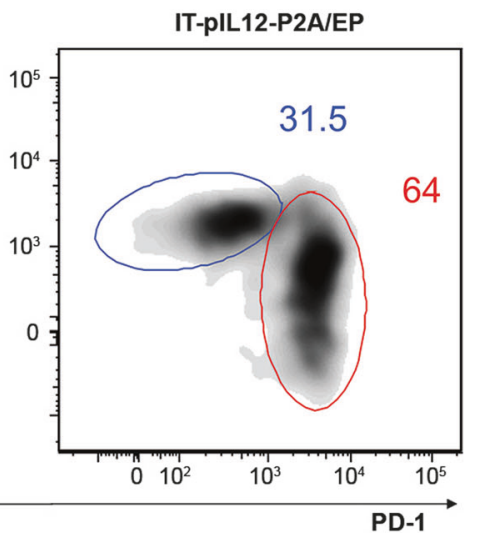

b

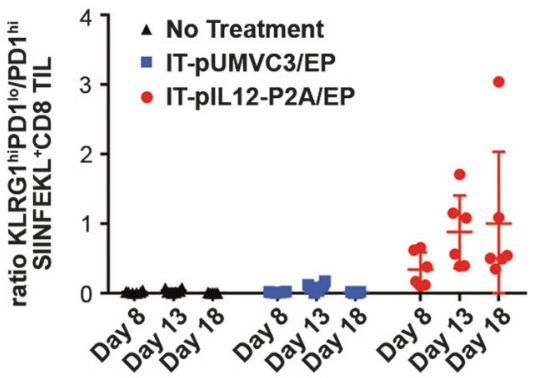

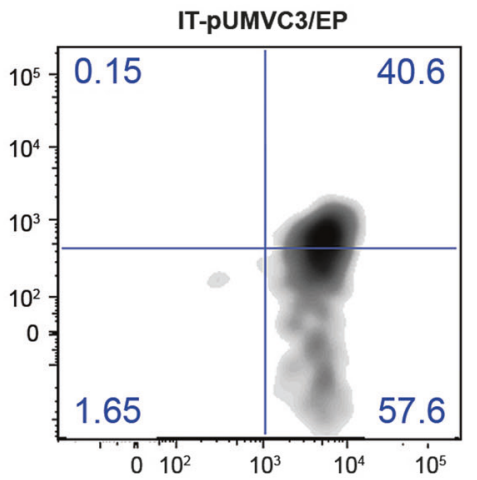
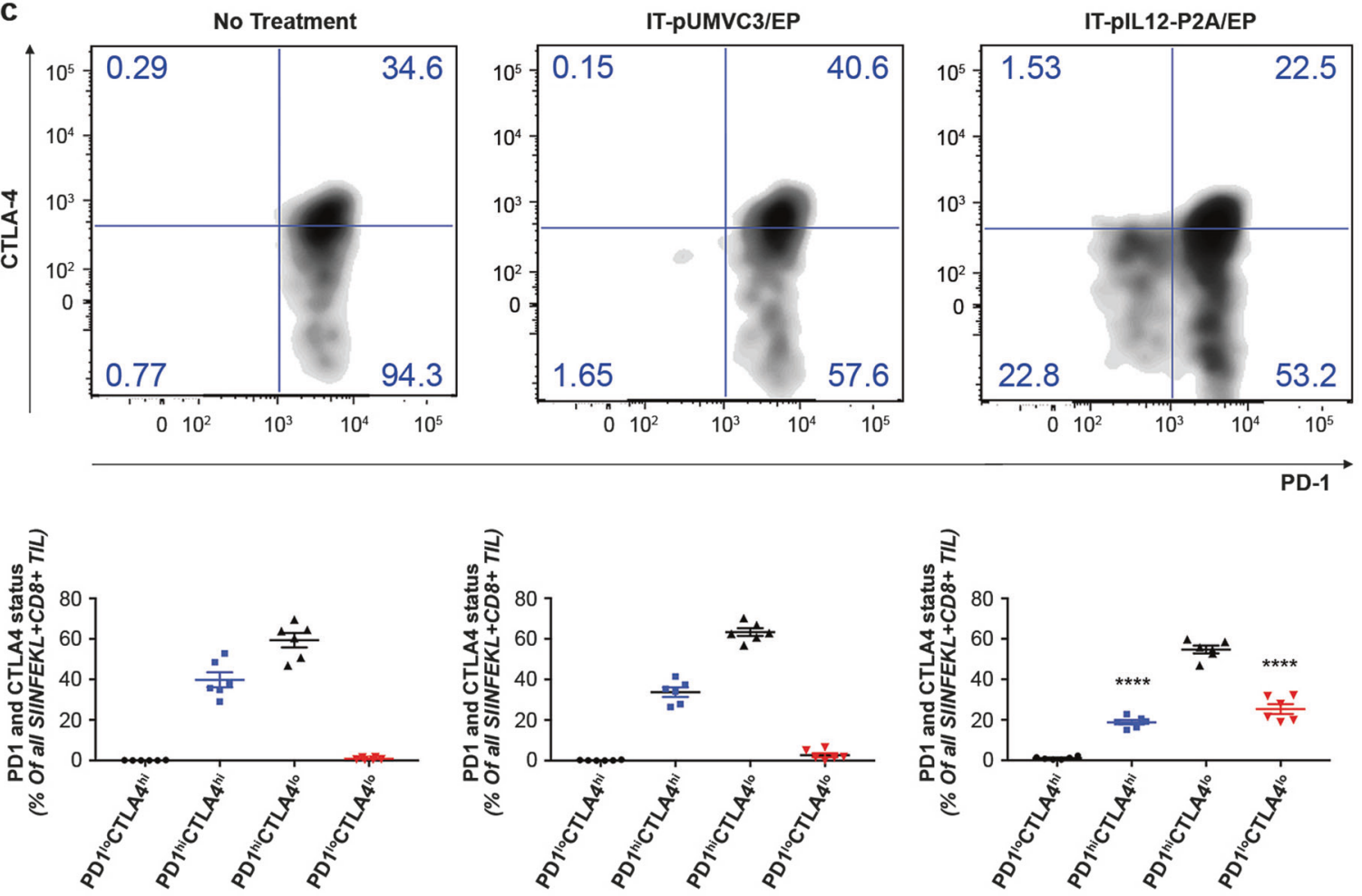

Fig. 7 IT-pIL12/EP enriched for $\mathrm{KLRG}^{\text {hi }} \mathrm{CD}^{+} \mathrm{T}$ cells in the contralateral tumors that were PD- $1^{\text {lo }}$, CTLA- $4^{\text {lo }}$. Lymphocyte fractions were isolated from excised, tumors 8,13 and 18 days post EP from B16-OVA tumor-bearing mice, which had been treated with IT-pIL12P2A-EP or IT-pUMVC3/EP of the tumors on the opposite flank, or left untreated (no treatment) and analyzed by flow cytometry. a Representative density plots show relative KLRG1 ( $y$ axis) and PD-1 ( $x$ axis) cell surface marker staining for all SIINFEKL ${ }^{+} \mathrm{CD}^{+}$TIL from ITpIL12/EP (right panel) and IT-pUMVC3/EP (left panel) treated mice on day 18 . Gating for KLRG $1^{\text {hi }} \mathrm{PD}-1^{\mathrm{lo}}$, and $\mathrm{PD}-1^{\text {hi }}$ populations are shown as blue and red ovals, respectively. Parent populations are all $\mathrm{LIVE} / \mathrm{CD} 19^{\mathrm{NEG}} / \mathrm{NK} 1.1^{\mathrm{NEG}} / \mathrm{CD} 3^{+} / \mathrm{CD} 8^{+}$TIL. Presence of these KLRG $1{ }^{\text {hi }} \mathrm{PD}-1^{\text {lo }}$ satellite populations were seen in IT-pIL12/EP-treated mice in two other independent electroporation experiments. b Scatter plots show the ratios of KLRG $1^{\text {hi }} \mathrm{PD}-1^{\text {lo }} / \mathrm{PD}-1^{\text {hi }}$ in $\mathrm{SIINFEKL}^{+} \mathrm{CD} 8^{+}$ TIL at the time points indicated. All mice demonstrated measureable increase in this ratio at all time points measured. The numerical value

for ratios of the two populations in the untreated and pUMVC 3 cohorts (black and blue symbols) could not be accurately determined because the KLRG $1{ }^{\text {hi PD- }} 1^{\text {lo }}$ event count was $<50$ in most all mice so statistical analysis was not done. $\mathbf{c}$ Upper panels: representative density plots for PD-1 ( $x$ axis) vs. CTLA-4 ( $y$ axis) cell surface marker expression are shown for mice with no treatment (left), IT-pUMVC3/EP (middle), and IT-pIL12/EP (right) at 18 days post EP for all TIL that were LIVE $\mathrm{CD} 19^{\text {neg }} \mathrm{NK} 1.1^{\text {neg }} / \mathrm{CD}^{+} / \mathrm{CD}^{+} / \mathrm{SIINFEKL}^{+}$. Lower panels: the percentage of cells from quadrants shown for representative mice shown in upper panels are graphed below each panel as a mean \pm SEM for all mice; $n=6$ per cohort per time point. PD- 1 and CTLA- 4 doublepositive (hi) cells are shown in blue, and double-negative (lo) cells are shown in red. IT-pIL12/EP-treated mice had increased PD- $1{ }^{\text {lo }}$ CTLA $44^{\text {lo }}$ and decreased PD- $1{ }^{\text {hi }}$ CTLA $4{ }^{\text {hi }}$ populations when compared with both cohorts of control mice that was significant $(* * * * p<0.0001$, one-way ANOVA) (color figure online) 
of successful T cells priming with IL-12 in situ in electroporated tumors.

IT-pIL12/EP treatment resulted in the generation of both $\mathrm{KLRG} 1{ }^{\mathrm{hi}} \mathrm{CD} 127^{\mathrm{NEG}}$, as well as a population of "doublepositive" KLRG1 ${ }^{\text {hi }} \mathrm{CD} 127^{+} \mathrm{CD} 8 \mathrm{~T}$ cells (data not shown). The significance of these phenotypes in the context of cancer immunotherapy remains unresolved, but similar $\mathrm{KLRG} 1{ }^{+} \mathrm{CD} 127^{\mathrm{NEG}}$ and $\mathrm{KLRG} 1^{+} \mathrm{CD} 127^{+} \mathrm{CD} 8$ s effector cell populations have been identified in various viral infection models and named short-lived effector cells (SLECs) and double-positive effector cells (DPECs), respectively [24]. SLECs, as the name connotes, are thought to be highly potent, terminally differentiated cytotoxic $\mathrm{T}$ cells, which have limited proliferative potential and do not contribute to the formation of long-term memory precursor populations [36]. There is evidence for KLRG1 as not only an effector T-cell marker, but also one for terminal differentiation and senescence in T cells, and KLRG1 has been shown to act as a co-receptor to inhibit cytotoxic function of T cells toward E-cadherin-expressing cells [37]. Currently, it remains unclear whether the KLRG1 ${ }^{\text {hi }}$ CD8's produced by IT-pIL12/EP represent classical SLECs and DPECs or have more "promiscuous CTL traits" as previously ascribed to IL-12-primed CD8's [23, 38].

Flow cytometric analysis of the baseline SIINFEKL ${ }^{+}$ CD8 population detected in the distant, untreated B16F10OVA tumors from control animals (IT-pUMVC3/EP) revealed a single major PD- ${ }^{\text {hi }}$ population, which based on PD- $1^{\text {hi }}$ status and co-expression of other T-cell checkpoint receptors (CTLA-4, LAG-3, TIM3) likely represents CD8 $\mathrm{T}$ cells in various stages of evolving exhaustion/dysfunction. We would expect to observe a PD- ${ }^{\text {hi }}$ phenotype on infiltrating SIINFEKL-reactive KLRG $1^{\text {hi }}$ CD8 $\mathrm{T}$ cells due to either (1) activation upon re-encounter with antigen (i.e., OVA) or (2) exhaustion due to re-encounter with antigen in the presence of increased PD-L1 expression. Contrary to this expectation, however, many of the SIINFEKL ${ }^{+}$ KLRG1 ${ }^{\text {hi }}$ CD8 $\mathrm{T}$ cells in the IT-pIL12/EP group express distinctly low, but non-negative, levels of PD-1, as well as diminished expression of multiple T-cell other checkpoint proteins, including CTLA-4, Lag-3, and Tim3 (Fig. 7 and S7). Although the mechanism of this coordinated downregulation of checkpoint molecules remains to be established, Blimp-1 has been shown to be capable of physically displacing Nuclear factor of activated T-cells (NFAT-1C) from the PD-1 promoter, leading to decreased transcription of PD-1 [39]. Similarly, as NFAT-binding sites are present in the promoter regions of CTLA-4, Tim-3, and Lag-3 [40, 41], IL-12-mediated overexpression of Blimp-1 during Tcell priming in electroporated tumors may represent the common mechanism. At this juncture, we do not know if these KLRG $1^{\text {hi }}$ PD- $1^{\text {lo }}$ CD8 TIL increase their PD-1 expression over time as they persist in the tumor, eventually converting to a PD- $1^{\text {hi }}$ exhausted state.

It is interesting to consider whether the IL-12-dependent downregulation of PD-1 (and other checkpoints) on the KLRG1 1 hi CD8 TIL plays a role in "armoring" these particular effector $\mathrm{CD}^{+} \mathrm{T}$ cells against $\mathrm{T}$-cell checkpoints, contributing to their potent antitumor effects. Clearly, a paper by Gerner et al. suggests that this may, in fact, be the case [34]. These authors studied the antitumor effect of adoptive transfer of $\mathrm{CD}^{+} \mathrm{T}$ cells primed in the presence of either IL-12 or IFN- $\alpha$ in the B16F10 model. OT-1 T cells primed with $\mathrm{K}^{\mathrm{b}}$-SIINFEKL together with CD80 in the presence of IL-12 (compared with IFN- $\alpha$ ) are more effective antitumor CTL because they are programmed during the priming phase in some manner to limit their expression of PD-1 upon re-encountering antigen in the TME. Thus, antiPD-L1 blockade fails to improve the antitumor effects of IL-12-primed OT-1 cells, whereas it rescues IFN- $\alpha$-primed OT-1 CTL activity to the level of IL-12-primed cells. Other studies confirm enhanced antitumor activity of PD- $1^{\text {lo }} \mathrm{CD} 8$ effector T cells compared with PD- ${ }^{\text {hi }}$ [42-44].

Here, we provide evidence that localized IT IL-12 expression in ELs led to the generation and dissemination of TAA-KLRG $1{ }^{\text {hi }} \mathrm{CD} 8^{+}$effector T cells in both the spleen and distant contralateral TILs. Interestingly, a significant abscopal effect was observed in the contralateral tumor despite induction of adaptive resistance (characterized by IFN- $\gamma$-responsive genes including PD-L1). We hypothesize that this potent antitumor effect on the distant, contralateral tumors may be orchestrated, at least in part, by highly activated $\mathrm{KLRG} 1{ }^{\text {hi }} \mathrm{CD}^{+} \mathrm{T}$ cells that are able to downregulate expression of "checkpoint proteins" in a coordinated manner and thus be transiently resistant to multiple immune checkpoints, contributing to their fitness and longevity as antitumor CTL. Although other IL-12responsive cells likely play a contributing role in systemic tumor immunity generated with IT-pIL12/EP, we propose this $\mathrm{KLRG}^{\mathrm{hi}} \mathrm{CD}^{+} \mathrm{T}$ cells as a prominent mechanism of the abscopal effects of local IL-12 delivery in mice.

Fallon and co-workers have recently demonstrated that systemic IL-12 therapy (targeted to necrotic regions on the tumor) can synergize with anti-PD-L-1 checkpoint therapy in a mouse model [45]. In melanoma patients, who received IT electroporation-mediated IL-12 (Immunopulse ${ }^{\circledR}$ IL-12) and who subsequently received anti-PD-1 blockade were observed to have higher-than-expected PD-1 response rates [46, 47]. Although this study was retrospective, it suggests that, in at least some patients, IL-12 may have primed a subclinical antitumor immune response that was stalled until an anti-PD-1 agent was administered. Based on these data, the clinical benefit of IT electroporation of IL-12 in 
combination with pembrolizumab is being evaluated in advanced melanoma (NCT02493361; NCT03132675).

\section{Methods}

\section{Mice, tumor cell lines, contralateral model}

Female C57Bl/6J mice, 6-8 weeks of age (Jackson Laboratories) were housed in accordance with AALAM guidelines. B16F10 melanoma cells (CRL-6475; ATCC) were cultured with McCoy's 5A medium ( $2 \mathrm{mM}$ L-glutamine) with $10 \%$ fetal bovine serum (FBS) and $50 \mu \mathrm{g} / \mathrm{ml}$ gentamicin. Murine B16F10-OVA melanoma cell lines (a gift from Heat Biologics) were established by transfecting B16F10 cells with full-length ovalbumin and selecting for stable transformants [48], and were cultured in Iscove's Modified Dulbecco's Medium (IMDM) $+10 \%$ FBS +2 $\mathrm{mg} / \mathrm{ml} \mathrm{G} 418$. Cells were harvested with $0.25 \%$ trypsin and re-suspended in Hank's balanced salt solution. Anesthetized mice were subcutaneously injected with 1 million cells and 0.25 million cells each in a total volume of $0.1 \mathrm{ml}$ into the right and left flank of each mouse, respectively. Tumor growth was monitored by digital caliper measurements. Tumor volume $\left(V_{T}\right)$ was calculated using he formula $V_{T}=$ $a^{2} \times \mathrm{b} / 2$, where $a=$ smallest diameter and $b=$ perpendicular diameter. Mice with tumors ranging from 100 to $160 \mathrm{~mm}^{3}$ (right) and 30 to $35 \mathrm{~mm}^{3}$ (left) were randomized and divided into treatment groups. This protocol was used as a standard model to test simultaneously for the effect on the EL and contralateral lesion (CL). Tumor volumes were measured twice weekly. Mice were euthanized when the total tumor burden reached $1500 \mathrm{~mm}^{3}$.

\section{Plasmids (pIL12-P2A and pUMVC3)}

Mouse IL-12p35 and p40 gBlock DNA fragments were obtained from Integrated DNA Technologies, Inc. (Coralville, IA) and cloned into pUMVC3 plasmid (Aldveron, Fargo, ND) separated by a transcription modifier sequence, P2A (Burkart et al. [16] and supplemental methods).

\section{IT treatment}

Mice were anesthetized with 3\% isoflurane for treatment. In all, $50 \mu \mathrm{g}$ of circular plasmid DNA, diluted to $1 \mu \mathrm{g} / \mu \mathrm{l}$ in sterile $0.9 \%$ saline, was injected centrally into primary tumors using a $1 \mathrm{ml}$ syringe with a 26-gauge needle. EP followed immediately after plasmid DNA injection, using a BTX ECM 830 square wave generator (Harvard Apparatus) or GENESIS square wave generator (OncoSec Medical Incorporated) to deliver eight unidirectional pulses $(400 \mathrm{~V} /$ $\mathrm{cm}, 10 \mathrm{~ms}$ ) using a four-needle electrode array.

\section{Tumor lysis for protein extraction and cytokine analysis by ELISA}

Forty-eight hours after IT-EP, tumors were dissected from mice and frozen in liquid nitrogen. In all, $300 \mu \mathrm{l}$ of tumor lysis buffer $(50 \mathrm{mM}$ TRIS $\mathrm{pH} 7.5,150 \mathrm{mM} \mathrm{NaCl}, 1 \mathrm{mM}$ EDTA, $0.5 \%$ Triton X-100, $1 \times$ Protease inhibitor cocktail) was added to the frozen tumor and homogenized on ice for $30 \mathrm{~s}$ (LabGen 710 homogenizer). Lysates were transferred to $1.5 \mathrm{ml}$ centrifuge tube and spun at $10,000 \times g$ for $10 \mathrm{~min}$ at $4{ }^{\circ} \mathrm{C}$. Supernatants were centrifuged and transferred to a new tube; this step was repeated three times. Tumor extracts were frozen at $-80^{\circ} \mathrm{C}$ or analyzed immediately according to manufacturer's instruction (mIL-12p70 DuoSet ELISA kit, DY419 and mIFN $\gamma$ DuoSet ELISA kit, DY485). The P2A ELISA was modified from a commercial mouse IL-12p70 ELISA (details in supplemental methods).

\section{RNA extraction and gene expression analysis}

Tumor tissue was harvested from mice using a scalpel and flash frozen in liquid nitrogen. Tissues were weighed, Trizol (Thermo Fisher Scientific, Waltham, MA) was added and tissue was homogenized using a probe homogenizer on ice. RNA was extracted from Trizol using manufacturer's instructions. Contaminating DNA was removed with DNase (Thermo Fisher, cat no.: EN0525). Gene expression profiling was performed using NanoString ${ }^{\oplus}$ technology. (nCounter code sets; details in supplemental methods).

\section{Histology and immunohistochemistry}

Tumors were fixed in $10 \%$ neutral buffered formalin and embedded in paraffin according to standard procedures. Five micron sections were stained with $\mathrm{H} \& \mathrm{E}$ to assess tissue and cellular morphology. Immunohistochemistry to detect CD8a was performed using a polyclonal rat antibody (14-0808-82, eBiosciences; details in supplemental methods).

\section{Splenic lymphocytes and TIL isolation, staining for flow cytometric analysis}

Spleen cells were isolated by pressing spleens through a $70 \mu \mathrm{m}$ filter, followed by red blood cell lysis (RBC lysis buffer, VWR, 420301OBL). Tumors were dissociated using Gentle-MACS (Miltenyi tumor dissociation kit 130-096730, C-tubes, 130-093-237) and homogenized using a Miltenyi gentleMACS ${ }^{\mathrm{TM}}$ Octo Dissociator with Heaters (130-096-427). Both tumor and spleen cell suspensions were fractionated with lympholyte-M (Cedarlane CL5035) and lymphocyte layers were washed and re-suspended in 
phosphate-buffered saline containing $2 \%$ FBS and $1 \mathrm{mM}$ EDTA with $1 \times / \mathrm{mL}$ Fc block (eBioscience 14-0161-85) on ice. In 96-well plates, cells were mixed with a solution of SIINFEKL or control tetramer (MBL T03002 or T03000, TS-M008-2), according to the manufacturer's instruction, and stained with antibody cocktails (details in supplemental methods). Data analysis was done using FlowJo software (TreeStar).

Acknowledgements We would like to thank the Fred Hutchinson Cancer Research Center Experimental Histopathology Laboratory for excellent performance of histology and IHC (supported in part by CCSG grant P30 CA015704). We would like to thank Issac Mohar, $\mathrm{PhD}$, for help with flow cytometric data acquisition and analysis.

Author contributions AM, SS, and JW contributed equally to experimental design, data analyses and manuscript preparation. DAC was involved in DNA plasmid design and manuscript preparation. CB and RJC were involved in optimizing gene electrotransfer conditions. JSC and RHP were involved in experimental design and manuscript preparation. RHP serves as the corresponding author.Data availabilityThe datasets supporting the conclusions of this article are included within the article.

\section{Compliance with ethical standards}

Conflict of interest All authors are past or present employees of OncoSec Medical Incorporated. Dr. Canton, Dr. Connolly, Dr. Campbell, and Dr. Pierce are inventors on patent applications.

Ethics approval The animal protocol number is EB15-063. To ensure refinement of experimental procedures, the animal husbandry and all experimental procedures were conducted under the guidelines described in: The Guide for Care and use of Laboratory Animals 8th Edition and The Animal Welfare Act $(9$ CFR, Part 1, 2). In this protocol, the animal housing and husbandry were performed by Explora BioLabs. All standard operating procedures have been approved by Explora's IACUC.

Open Access This article is licensed under a Creative Commons Attribution 4.0 International License, which permits use, sharing, adaptation, distribution and reproduction in any medium or format, as long as you give appropriate credit to the original author(s) and the source, provide a link to the Creative Commons license, and indicate if changes were made. The images or other third party material in this article are included in the article's Creative Commons license, unless indicated otherwise in a credit line to the material. If material is not included in the article's Creative Commons license and your intended use is not permitted by statutory regulation or exceeds the permitted use, you will need to obtain permission directly from the copyright holder. To view a copy of this license, visit http://creativecommons. org/licenses/by/4.0/.

\section{References}

1. Atkins MB, Robertson MJ, Gordon M, Lotze MT, DeCoste M, DuBois JS, et al. Phase I evaluation of intravenous recombinant human interleukin 12 in patients with advanced malignancies. Clin Cancer Res. 1997;3:409-17.

2. Leonard JP, Sherman ML, Fisher GL, Buchanan LJ, Larsen G, Atkins MB, et al. Effects of single-dose interleukin-12 exposure on interleukin-12-associated toxicity and interferon-gamma production. Blood. 1997;90:2541-8.

3. Hurteau JA, Blessing JA, DeCesare SL, Creasman WT. Evaluation of recombinant human interleukin-12 in patients with recurrent or refractory ovarian cancer: a gynecologic oncology group study. Gynecol Oncol. 2001;82:7-10.

4. Rosenberg SA. Cell therapy for metastatic melanoma using CD8 enriched tumor infiltrating lymphocytes. In: Health NIo, ed. ClinicalTrials.gov, 2015.

5. Daud AI, DeConti RC, Andrews S, Urbas P, Riker AI, Sondak VK, et al. Phase I trial of interleukin-12 plasmid electroporation in patients with metastatic melanoma. J Clin Oncol. 2008;26:5896903.

6. Daud AIAA, Ashworth MT, Fong L, Lewis J, Chan SE, et al. Systemic antitumor effect and clinical response in a phase 2 trial of intratumoral electroporation of plasmid interleukin-12 in patients with advanced melanoma. J Clin Oncol. 2014;32:90259025.

7. Sin JI, Park JB, Lee IH, Park D, Choi YS, Choe J, et al. Intratumoral electroporation of IL-12 cDNA eradicates established melanomas by Trp2(180-188)-specific CD8 + CTLs in a perforin/ granzyme-mediated and IFN-gamma-dependent manner: application of Trp2(180-188) peptides. Cancer Immunol Immunother. 2012;61:1671-82.

8. Lucas ML, Heller R. IL-12 gene therapy using an electrically mediated nonviral approach reduces metastatic growth of melanoma. DNA Cell Biol. 2003;22:755-63.

9. Goto T, Nishi T, Kobayashi O, Tamura T, Dev SB, Takeshima H, et al. Combination electro-gene therapy using herpes virus thymidine kinase and interleukin-12 expression plasmids is highly efficient against murine carcinomas in vivo. Mol Ther. 2004;10:929-37.

10. Kim H, Sin JI. Electroporation driven delivery of both an IL-12 expressing plasmid and cisplatin synergizes to inhibit B16 melanoma tumor growth through an NK cell mediated tumor killing mechanism. Hum Vaccin Immunother. 2012;8:1714-21.

11. Obana S, Miyazawa H, Hara E, Tamura T, Nariuchi H, Takata M, et al. Induction of anti-tumor immunity by mouse tumor cells transfected with mouse interleukin-12 gene. Jpn J Med Sci Biol. 1995;48:221-36.

12. Pavlin D, Cemazar M, Kamensek U, Tozon N, Pogacnik A, Sersa G. Local and systemic antitumor effect of intratumoral and peritumoral IL-12 electrogene therapy on murine sarcoma. Cancer Biol Ther. 2009;8:2114-22.

13. Tamura T, Nishi T, Goto T, Takeshima H, Dev SB, Ushio Y, et al. Intratumoral delivery of interleukin 12 expression plasmids with in vivo electroporation is effective for colon and renal cancer. Hum Gene Ther. 2001;12:1265-76.

14. Lucas ML, Heller L, Coppola D, Heller R. IL-12 plasmid delivery by in vivo electroporation for the successful treatment of established subcutaneous B16.F10 melanoma. Mol Ther. 2002;5:66875.

15. Pierce RH, Campbell JS, Pai SI, Brody JD, Kohrt HE. In-situ tumor vaccination: bringing the fight to the tumor. Hum Vaccin Immunother. 2015;11:1901-9.

16. Burkart C, Mukhopadhyay A, Shirley SA, Connolly RJ, Wright $\mathrm{JH}$, Bahrami A, et al. Improving therapeutic efficacy of IL-12 intratumoral gene electrotransfer through novel plasmid design and modified parameters. Gene Ther. 2018;25:93-103.

17. Weaver JC, Smith KC, Esser AT, Son RS, Gowrishankar TR. A brief overview of electroporation pulse strength-duration space: a region where additional intracellular effects are expected. Bioelectrochemistry. 2012;87:236-43.

18. Grohmann U, Belladonna ML, Vacca C, Bianchi R, Fallarino F, Orabona C, et al. Positive regulatory role of IL-12 in macrophages and modulation by IFN-gamma. J Immunol. 2001;167:221-7. 
19. Macatonia SE, Hosken NA, Litton M, Vieira P, Hsieh CS, Culpepper JA, et al. Dendritic cells produce IL-12 and direct the development of Th1 cells from naive CD4+T cells. J Immunol. 1995;154:5071-9.

20. Yang Y, Ochando JC, Bromberg JS, Ding Y. Identification of a distant T-bet enhancer responsive to IL-12/Stat4 and IFNgamma/ Stat1 signals. Blood. 2007;110:2494-500.

21. Xin A, Masson F, Liao Y, Preston S, Guan T, Gloury R, et al. A molecular threshold for effector CD8(+) T-cell differentiation controlled by transcription factors Blimp-1 and T-bet. Nat Immunol. 2016;17:422-32.

22. Watford WT, Hissong BD, Bream JH, Kanno Y, Muul L, O'Shea JJ. Signaling by IL-12 and IL-23 and the immunoregulatory roles of STAT4. Immunol Rev. 2004;202:139-56.

23. Herndler-Brandstetter D, Ishigame H, Shinnakasu R, Plajer V, Stecher C, Zhao J, et al. KLRG1(+) effector CD8(+) T cells lose KLRG1, differentiate into all memory $\mathrm{T}$ cell lineages, and convey enhanced protective immunity. Immunity. 2018;48:716-729 e8.

24. Joshi NS, Cui W, Chandele A, Lee HK, Urso DR, Hagman J, et al. Inflammation directs memory precursor and short-lived effector $\mathrm{CD} 8(+) \mathrm{T}$ cell fates via the graded expression of T-bet transcription factor. Immunity. 2007;27:281-95.

25. Gros A, Robbins PF, Yao X, Li YF, Turcotte S, Tran E, et al. PD1 identifies the patient-specific $\mathrm{CD} 8(+)$ tumor-reactive repertoire infiltrating human tumors. J Clin Invest. 2014;124:2246-59.

26. Daud AI, Loo K, Pauli ML, Sanchez-Rodriguez R, Sandoval PM, Taravati K, et al. Tumor immune profiling predicts response to anti-PD-1 therapy in human melanoma. J Clin Invest. 2016;126:3447-52.

27. Daud AAA, Ashworth MT, Fong L, Lewis J, Chan SE, et al. Systemic anti-tumor effect and clinical response in a phase 2 trial of intratumoral electroporation of plasmid interleukin-12 in patients with advanced melanoma. Am Soc Clin Oncol. 2014;32:9025-9025.

28. Canton DA, Shirley S, Wright J, Connolly R, Burkart C, Mukhopadhyay A, et al. Melanoma treatment with intratumoral electroporation of tavokinogene telseplasmid (pIL-12, tavokinogene telseplasmid). Immunotherapy. 2017;9:1309-21.

29. Castle JC, Kreiter S, Diekmann J, Lower M, van de Roemer N, de Graaf J, et al. Exploiting the mutanome for tumor vaccination. Cancer Res. 2012;72:1081-91.

30. Agrawal S, Reemtsma K, Bagiella E, Oluwole SF, Braunstein NS. Role of TAP-1 and/or TAP-2 antigen presentation defects in tumorigenicity of mouse melanoma. Cell Immunol. 2004;228:130-7.

31. Zika E, Ting JP. Epigenetic control of MHC-II: interplay between CIITA and histone-modifying enzymes. Curr Opin Immunol. 2005; 17:58-64.

32. Kerkar SP, Goldszmid RS, Muranski P, Chinnasamy D, Yu Z, Reger RN, et al. IL-12 triggers a programmatic change in dysfunctional myeloid-derived cells within mouse tumors. J Clin Invest. 2011;121:4746-57.

33. Diaz-Montero CM, El Naggar S, Al Khami A, El Naggar R, Montero AJ, Cole DJ, et al. Priming of naive CD8 $+\mathrm{T}$ cells in the presence of IL-12 selectively enhances the survival of CD8 + CD62Lhi cells and results in superior anti-tumor activity in a tolerogenic murine model. Cancer Immunol Immunother. 2008;57:563-72.
34. Gerner MY, Heltemes-Harris LM, Fife BT, Mescher MF. Cutting edge: IL-12 and type I IFN differentially program CD8 T cells for programmed death 1 re-expression levels and tumor control. J Immunol. 2013;191:1011-5.

35. Rubinstein MP, Cloud CA, Garrett TE, Moore CJ, Schwartz KM, Johnson CB, et al. Ex vivo interleukin-12-priming during CD8(+) $\mathrm{T}$ cell activation dramatically improves adoptive $\mathrm{T}$ cell transfer antitumor efficacy in a lymphodepleted host. J Am Coll Surg. 2012;214:700-7.

36. Joshi NS, Kaech SM. Effector CD8 T cell development: a balancing act between memory cell potential and terminal differentiation. J Immunol. 2008;180:1309-15.

37. Reiser J, Banerjee A. Effector, memory, and dysfunctional CD8 $(+) \mathrm{T}$ cell fates in the antitumor immune response. $\mathrm{J}$ Immunol Res. 2016;2016:8941260.

38. Diaz-Montero CM, Naga O, Zidan AA, Salem ML, Pallin M, Parmigiani A, et al. Synergy of brief activation of CD8 T cells in the presence of IL-12 and adoptive transfer into lymphopenic hosts promotes tumor clearance and anti-tumor memory. Am J Cancer Res. 2011;1:882-96.

39. Oestreich KJ, Yoon H, Ahmed R, Boss JM. NFATc1 regulates PD-1 expression upon $\mathrm{T}$ cell activation. $\mathrm{J}$ Immunol. 2008;181:4832-9.

40. Gibson HM, Hedgcock CJ, Aufiero BM, Wilson AJ, Hafner MS, Tsokos GC, et al. Induction of the CTLA-4 gene in human lymphocytes is dependent on NFAT binding the proximal promoter. $\mathrm{J}$ Immunol. 2007;179:3831-40.

41. Martinez GJ, Pereira RM, Aijo T, Kim EY, Marangoni F, Pipkin ME, et al. The transcription factor NFAT promotes exhaustion of activated CD8 $(+)$ T cells. Immunity. 2015;42:265-78.

42. Blackburn SD, Shin H, Freeman GJ, Wherry EJ. Selective expansion of a subset of exhausted CD8 T cells by alphaPD-L1 blockade. Proc Natl Acad Sci USA. 2008;105:15016-21.

43. Blackburn SD, Shin H, Haining WN, Zou T, Workman CJ, Polley $\mathrm{A}$, et al. Coregulation of CD8 $+\mathrm{T}$ cell exhaustion by multiple inhibitory receptors during chronic viral infection. Nat Immunol. 2009;10:29-37.

44. Paley MA, Kroy DC, Odorizzi PM, Johnnidis JB, Dolfi DV, Barnett BE, et al. Progenitor and terminal subsets of CD8 + $\mathrm{T}$ cells cooperate to contain chronic viral infection. Science. 2012;338:1220-5

45. Fallon JK, Vandeveer AJ, Schlom J, Greiner JW. Enhanced antitumor effects by combining an IL-12/anti-DNA fusion protein with avelumab, an anti-PD-L1 antibody. Oncotarget. 2017;8:20558-71.

46. Chen L, Daud A. A review of novel intralesional therapies for melanoma, with an emphasis on a potential combination approach. Oncology (Williston Park). 2016;30:442-3.

47. Alain Algazi KKT, Kathryn T T, L Chen, C Twitty, M Dwyer, S Greaney, et al. Intratumoral electroporation of plasmid IL-12 can prime response to anti-PD1/PD-L1 blockade in patients with Stage III/IV-M1a melanoma. [abstract]. In: Proceedings of the 107th Annual Meeting of the American Association for Cancer Research; 2016 Apr 16-20; New Orleans, LA. Philadelphia (PA): AACR; Cancer Res 2016;76(14 Suppl):Abstract nr CT134.

48. Fromm G, de Silva S, Giffin L, Xu X, Rose J, Schreiber TH Gp96-Ig/costimulator (OX40L, ICOSL, or 4-1BBL) combination vaccine improves $\mathrm{T}$-cell priming and enhances immunity, memory, and tumor elimination. Cancer Immunol Res. 2016;4:766-78. 